University of Wollongong

Research Online

Faculty of Engineering and Information

Faculty of Engineering and Information

Sciences - Papers: Part A

Sciences

2017

Development of a dynamic model for a hybrid photovoltaic thermal collector - Solar air heater with fins

Wenke Fan

University of Wollongong,wf303@uowmail.edu.au

Georgios Kokogiannakis

University of Wollongong, gkg@uow.edu.au

Zhenjun Ma

University of Wollongong, zhenjun@uow.edu.au

Paul Cooper

University of Wollongong, pcooper@uow.edu.au

Follow this and additional works at: https://ro.uow.edu.au/eispapers

Part of the Engineering Commons, and the Science and Technology Studies Commons

Research Online is the open access institutional repository for the University of Wollongong. For further information contact the UOW Library: research-pubs@uow.edu.au 


\title{
Development of a dynamic model for a hybrid photovoltaic thermal collector - Solar air heater with fins
}

\begin{abstract}
A dynamic model for a hybrid Photovoltaic Thermal Collector-Solar Air Heater (PVT-SAH) with longitudinal fins was developed to enable assessment of the potential of the system to provide high temperature outlet air $\left(60-90^{\circ} \mathrm{C}\right)$ under dynamic boundary conditions. The model description includes the method for discretising the system into a number of control volumes, the energy balance equations for each control volume and the implementation of the numerical solution. Model validation has been successfully undertaken by using empirical verification of model predictions with an experimental facility and by comparing the model outputs with the reference data from the literature. The dynamic PVT-SAH model was then used under variable boundary conditions and its performance was compared with an equivalent steady state model. Significant Time Constants (TC) were observed and it was found that the steady state model could overestimate the thermal energy gains of PVT-SAH by $35 \%$ when compared with the predictions of the dynamic model. Additional simulations were run under fixed boundary conditions to shown the effect of fins on the performance of the PVT-SAH system. Finally, to demonstrate the benefits of using such a dynamic PVT-SAH model, a case study was used and the effect of length ratio of PVT to $\mathrm{SAH}$ was investigated by using a range of performance criteria.
\end{abstract}

\section{Keywords}

model, dynamic, hybrid, development, photovoltaic, thermal, collector, fins, heater, air, solar

\author{
Disciplines \\ Engineering | Science and Technology Studies
}

\section{Publication Details}

Fan, W., Kokogiannakis, G., Ma, Z. \& Cooper, P. (2017). Development of a dynamic model for a hybrid photovoltaic thermal collector - Solar air heater with fins. Renewable Energy, 101 816-834. 


\title{
Development of a dynamic model for a hybrid photovoltaic
}

\section{thermal collector - solar air heater with fins}

Wenke Fan*, Georgios Kokogiannakis, Zhenjun Ma, Paul Cooper

Sustainable Buildings Research Centre (SBRC), Faculty of Engineering and Information Sciences, University of Wollongong, Wollongong, NSW, 2522, Australia

*Corresponding author. Tel: +61 406144431

E-mail address:wf303@uowmail.edu.au

\begin{abstract}
A dynamic model for a hybrid Photovoltaic Thermal Collector-Solar Air Heater (PVT-SAH) with longitudinal fins was developed to enable assessment of the potential of the system to provide high temperature outlet air $\left(60-90^{\circ} \mathrm{C}\right)$ under dynamic boundary conditions. The model description includes the method for discretising the system into a number of control volumes, the energy balance equations for each control volume and the implementation of the numerical solution. Model validation has been successfully undertaken by using empirical verification of model predictions with an experimental facility and by comparing the model outputs with the reference data from the literature. The dynamic PVT-SAH model was then used under variable boundary conditions and its performance was compared with an equivalent steady state model. Significant Time Constants (TC) were observed and it was found that the steady state model could overestimate the thermal energy gains of PVT-SAH by $35 \%$ when compared with the predictions of the dynamic model. Additional simulations were run under fixed boundary conditions to shown the effect of fins on the performance of the PVT-SAH system. Finally, to demonstrate the benefits of using such a dynamic PVT-SAH model, a case study was used and the effect of length ratio of PVT to SAH was investigated by using a range of performance criteria.
\end{abstract}


Keywords: Photovoltaic Thermal-Solar air heater with fins; Dynamic control volume model; Model validation

\section{Nomenclature}

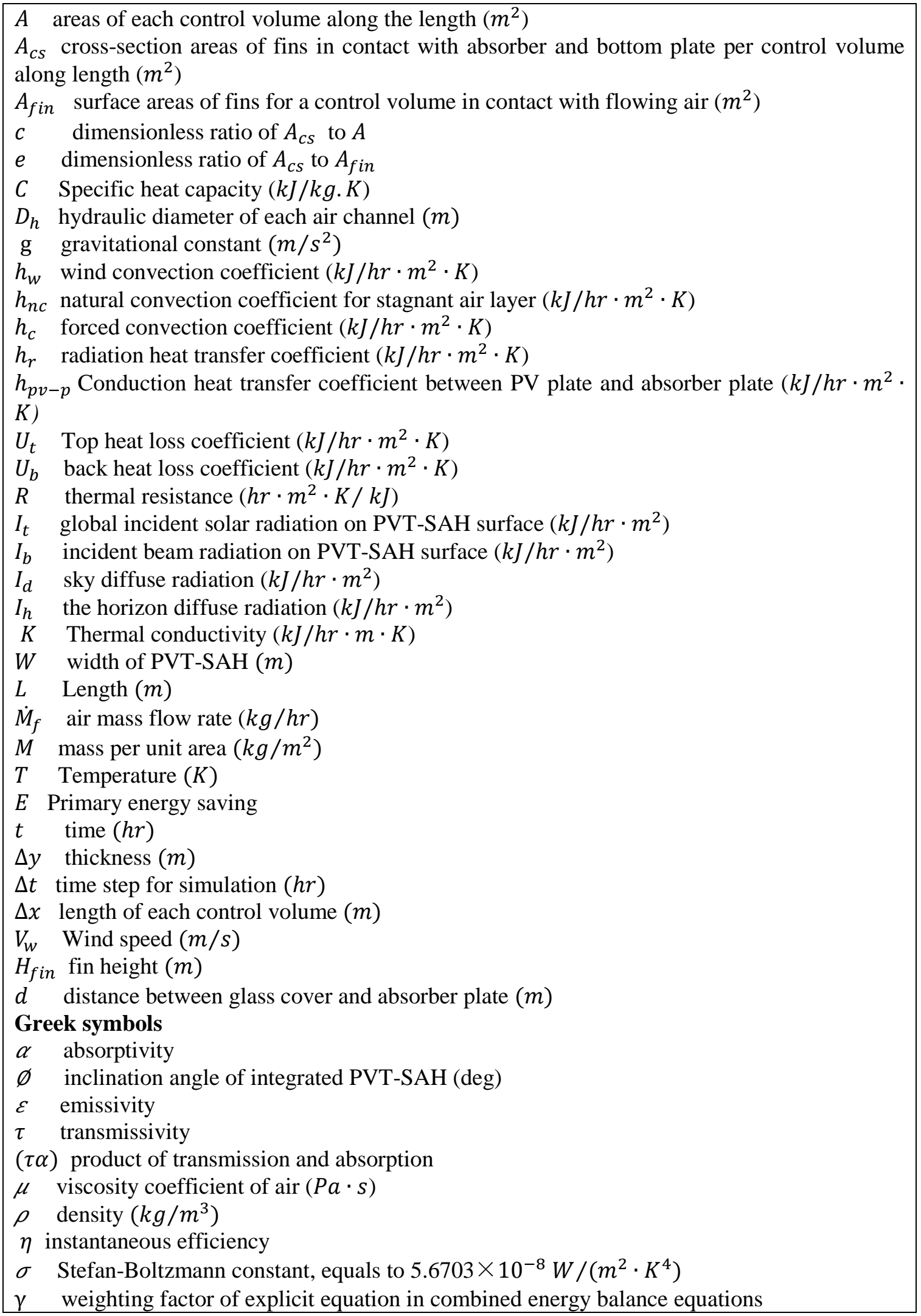




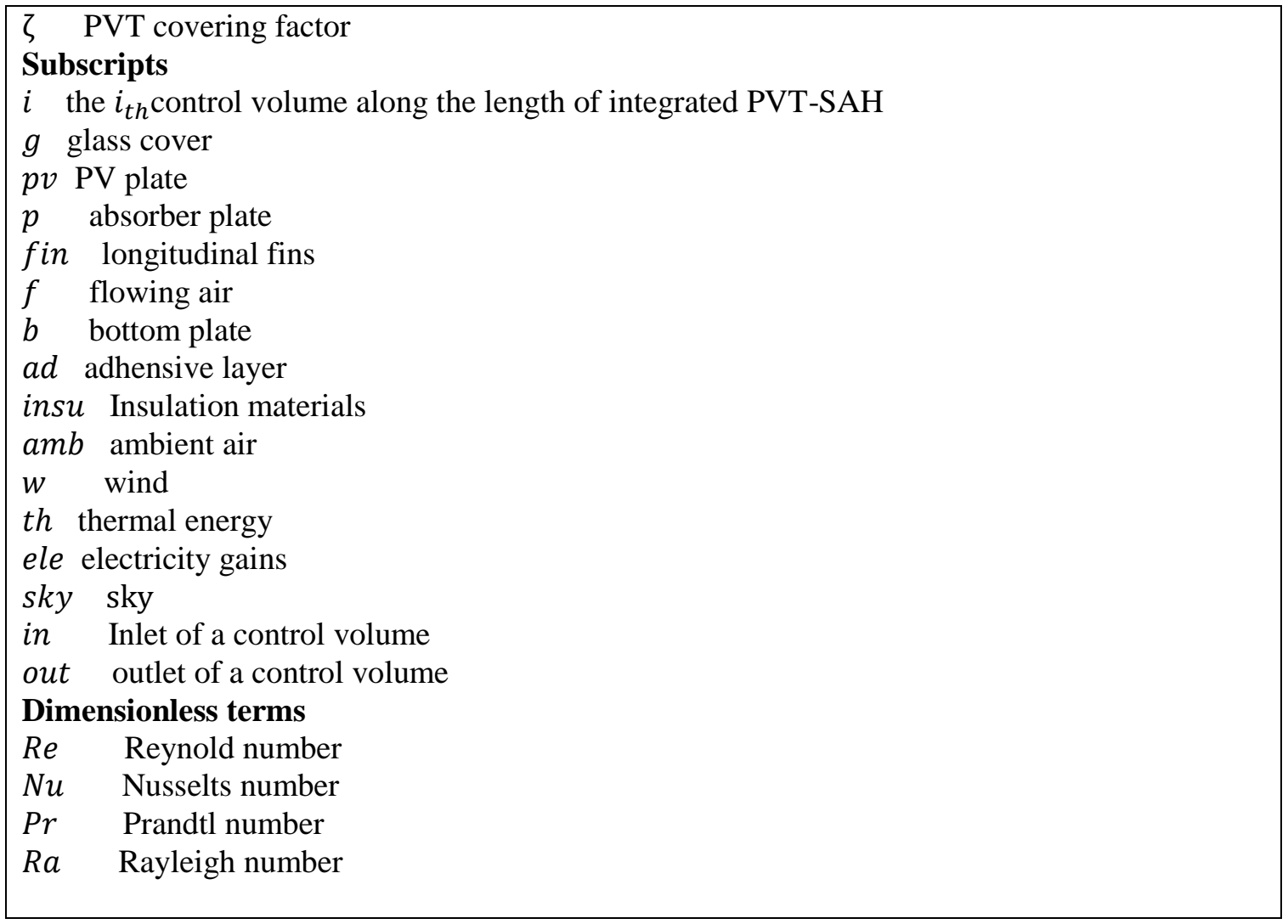




\section{Introduction}

Air based photovoltaic thermal (PVT) collectors utilise solar energy to generate both electricity and low grade thermal energy. The thermal energy collected from PVT collectors can be directly used for space heating or potentially used to drive desiccant wheels for space cooling of both residential and commercial buildings. However, a relatively high temperature energy source $\left(60-90^{\circ} \mathrm{C}\right)$ is often required in desiccant wheels for desiccant regeneration [1]. To achieve the target regeneration temperature, PVT systems can be connected in series. However, the local temperature of the PV absorber will increase with increasing PVT length. The excessive high temperature will bring challenges to the operation of PV panels, resulting in a decreased electrical efficiency, irreversible damages of the PV cells, and reduced lifespan of the PVT system. An alternative approach to achieving high outlet air temperature is to connect PVT systems with solar air heaters (SAH) in series. As the addition of fins has been considered as one of effective approaches to enhancing the thermal and electrical performance of PVT and SAH [2-9], the performance of the hybrid PVT-SAH system can be further enhanced by attaching longitude fins in the air channels to improve heat transfer between the absorber and the air flowing through the channels. A single layer of glass with a stagnant air layer between the glass cover and the PV absorber plate can also be used to increase the thermal resistance, and thereby further increase the temperature of the outlet air. A novel design of hybrid PVT-SAH system with fins is presented in Figure 1. The PVT and SAH have the same width, and the SAH is connected to the outlet of PVT in order to further increase the air temperature. The longitude fins are attached between the absorber plate and bottom plate of both PVT and SAH and divide the air channel into a number of small passages. 


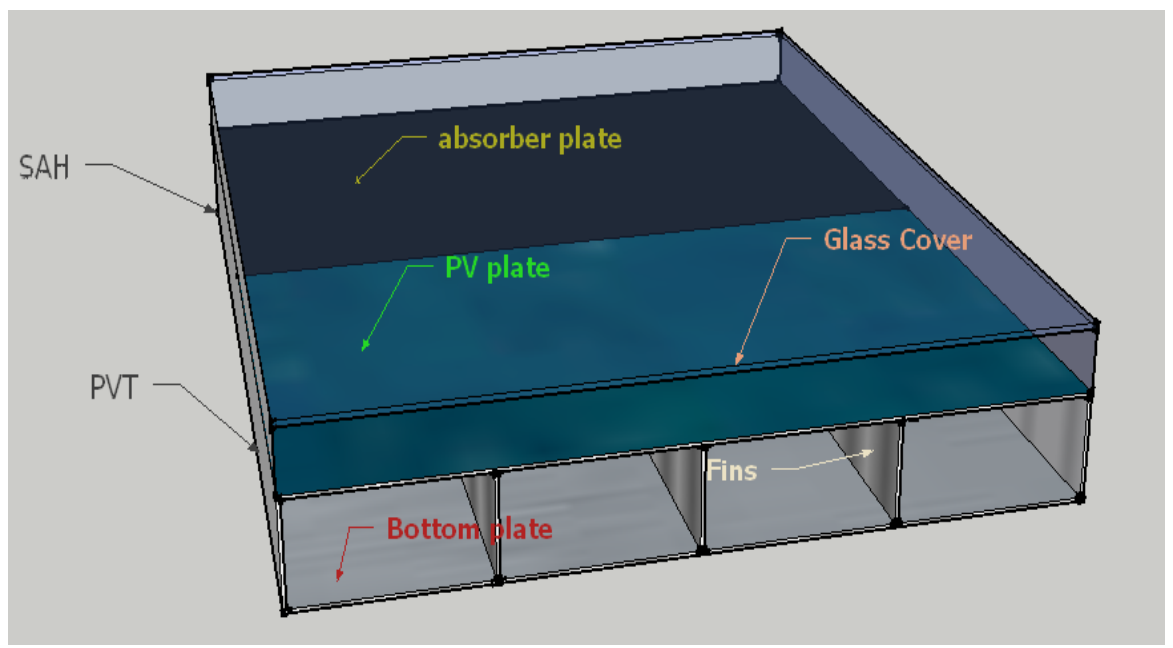

Figure 1 Schematic of a hybrid PVT-SAH system.

Numerical modelling and simulations have been widely used to evaluate the performance and optimise the design of PVT and SAH systems. Tchinca [10] provided a comprehensive review of mathematical models for different types of SAH systems. A high number of numerical simulations have also been conducted to investigate the thermal and electrical performance of PVT collectors [11-18]. However, most mathematical models developed in the previous studies were steady state models where the heat storage capacity of PVT and SAH is not considered. The output parameters of steady state models at each time step are only a function of design parameters and boundary conditions of the same time step, and do not account for the thermal inertia from the previous time steps. However, the weather conditions are subject to quick and frequent fluctuations within a short period, and the effect of the time constant of the PVT or SAH systems could be significant. In such cases, steady state models might lead to an over- or under- prediction of the thermal output. Schnieders [19] reported that compared with a dynamic model for SAHs, a steady state model could lead to up to $15 \%$ of overestimation of daily yield of thermal energy when one-minute input data was used. Applications where dynamic modelling is essential for PVT or SAH include: the investigation of operational control strategies, 
performance comparison with experiments working under dynamic weather conditions and interactions with other system components which often require dynamic output data from PVT or SAH as input parameters. For example, if a solar collector is connected with an auxiliary heater, the accurate prediction of the outlet fluid temperature from the solar collector will significantly influence the economical operation of the auxiliary heater. Despite the advantages of dynamic models for SAH and PVT systems, only a limited number of such models have been developed in the past.

This study presents the development of a dynamic model for a high-temperature PVT/SAH system with fins for potentially driving desiccant cooling systems. The dynamic model was developed using the finite volume method (FVM) via the unconditionally stable Crank Nicolson scheme. The performance of the model is validated using the data collected from a PVT test facility and the reference data reported in previous studies. This paper is structured as follows. In section 2, a brief overview of existing mathematical models for PVT and SAH is presented. Section 3 presents the development process of the dynamic model for the proposed hybrid PVTSAH system with fins and the detailed solution procedures. Section 4 describes the steps undertaken to validate the dynamic model and the resulted validation outputs. In section 5, the dynamic responses of the hybrid system to the changes of working conditions are analysed and the model outputs versus the outputs from an equivalent steady state model are compared. Section 6 investigates the effect of fin number and fin height on the electrical and thermal performance of the system. In section 7, a case study is used to examine the effect of PV covering factor on the thermal and electricity outputs of the whole PVT-SAH system and some conclusions were drawn at the end of the paper. 


\section{Overview of mathematical models for PVT and SAH}

Many efforts have been made on the development of appropriate mathematical models for PVT and SAH. In this section, the existing models were briefly reviewed by categorising them as steady state models, dynamic models and models that are based on CFD solvers.

\subsection{Existing steady state models}

A simple steady state model is sourced from Hottel-Whillier [20] where the thermal efficiency of solar air heaters was defined as a function of a heat removal factor, overall heat loss coefficient and inlet air temperature. Florschietz [21] made minor modifications to Hottel-Whillier model [20] so that it can be applicable to PVT. However, the analytical expressions for the heat removal factor and overall heat loss coefficient were only presented for sheet-tube type SAH and PVT systems. In engineering practice, a semi-empirical model in the same form of Hottel-Whillier equation [20] was applied to other types of SAH and PVT but the heat removal factor and the heat transfer coefficients were determined as constants through experiments following the procedures described in ASHRAE Standard [22] and the European EN 12975 Standard [23]. This implies that simulations using the semi-empirical model have to set their working conditions as similar as possible to the conditions under which the PVT and SAH are tested. Moreover, this semi-empirical model is not suitable for design optimisation due to a limited number of outputs. The application of this semi-empirical model can be found in TRNSYS [24] to simulate the performance of flat plate SAH ( Type 1) and evacuated tube SAH ( Type 71). In the past years, a significant number of steady state models with more flexibility and accuracy have been developed for different types of SAH and PVT, including models for unglazed/glazed [25-28], with fins [2-4, 29, 30], single/double pass [31-34] and 
with/without energy storage systems [35-38]. These steady state models described the phenomena occurring in PVT and SAH based on conservation of quantities (energy and mass). Analytical solutions and Gaussian elimination are the main methods used to obtain the various temperatures and derive the performance efficiency.

\subsection{Existing dynamic models}

Dynamic modelling is considered to be suitable for performance prediction of SAH and PVT under dynamic working conditions. The energy balance equations in dynamic models are generally represented with a set of partial differential equations. The solution of dynamic models requires the transformation of the partial difference equations into explicit, implicit or combined implicit/explicit forms. Despite a higher computational cost required and more complex implementation, dynamic models are suitable for design and control optimisations. There have been a number of dynamic models for PVT and SAH reported in literature [19, 39-44]. However, most of these models have not been developed in a way that allows for the modelling of fins in the air channels of PVT or SAH systems. In addition, the majority of the existing dynamic models $[42,43]$ deployed explicit finite difference techniques to solve the energy balance equations, and a small time step has to be used to avoid simulation instability. The solution procedures are inherently part of a dynamic model, however, the publications for the above mentioned dynamic models rarely provided detailed solution procedures.

\subsection{CFD-based models}

CFD software has also been used in previous studies to investigate the heat transfer and flow patterns in SAH [45-49] and PVT [50-52]. The results from CFD models provided extensive information on the velocity, pressure and temperature for any of the control volumes in the fluid domain of SAH or PVT systems. Using a CFD model 
for PVT and SAH has two major advantages: (1) an extensive number of outputs are available with regards to the heat transfer and flow dynamics in the flow channels; (2) complex air channel geometries (e.g. irregular shape of fins, surface roughness on the air channel) could be analysed. However, using CFD models could require significant computational resources for short-period simulations and they are not therefore suitable for real time control of a PVT-SAH system that is connected with other systems. Moreover, the selection of an appropriate turbulence model and meshing method is a key challenge, which could have a significant effect on the accuracy of the simulation results.

\section{Dynamic model development}

The above review revealed that dynamic models are the preferred option for performance assessment and design/control optimisation of PVT and SAH systems.

\subsection{Key assumptions used in model development}

The following assumptions are used in the model development.

- Heat transfer in a control volume occurs in one dimension perpendicular to the air flow direction of the PVT-SAH system with the exception of the flowing air where the heat transfer is happening both perpendicularly and parallel to the flow direction.

- The air is evenly distributed to each air channel and the air velocity in each air channel is identical.

- For each time step, the temperature of the flowing air, PV plate, absorber plate, fins, glass cover, and bottom plate is uniform over the width of the system but varies along the control volumes in the air flow direction.

- The heat conduction through the fins has a vertical direction from the absorber plate to the bottom plate. 
- There is no air leakage in the air channels and a good thermal contact between the PV plate and absorber plate is assumed.

- The heat loss through the PVT and SAH frame sides is negligible.

\subsection{Finite volume heat balance approach}

The hybrid PVT-SAH is first discretised into a finite number of control volumes along its length as shown in Figure 2. The boundary conditions for each discretised control volume are the same except for the inlet air temperature. The outlet air temperature of a control volume is assigned as the inlet air temperature of the next neighbouring control volume. The PVT is further discretised vertically into a finite number of nodes representing the glass cover (node ' $g$ '), the PV plate (node 'pv'), the absorber plate (node 'p'), the fins (node 'fin'), the air stream (node ' $\mathrm{f}$ ') and the bottom plate (node 'b'). As shown in Figure 3 (b), for the SAH control volumes the vertical discretisation is the same as that of PVT except that there is no PV plate node. For each node, a heat transfer balance equation is applied depending on the various forms of heat transfer process occurring on that node. Although these balance equations are in the discrete form, they are interlinked in nature. The set of equations will form a matrix where a simultaneous solution of the node temperature will be obtained for each time step. Section 3.3 will provide an example of how the heat transfer balance equations are developed for each node of the system and their final formulation into a form suitable for a simultaneous solution. The finite volume method (FVM) is employed to convert the partial difference energy balance equation of each node into a discretised form. Compared with other classical numerical schemes (e.g. finite difference method), FVM is more suitable for the physical problems that use energy and mass flow balances [53]. In addition, the FVM could be expanded to cover complex 2D or 3D problems and geometries [54]. 


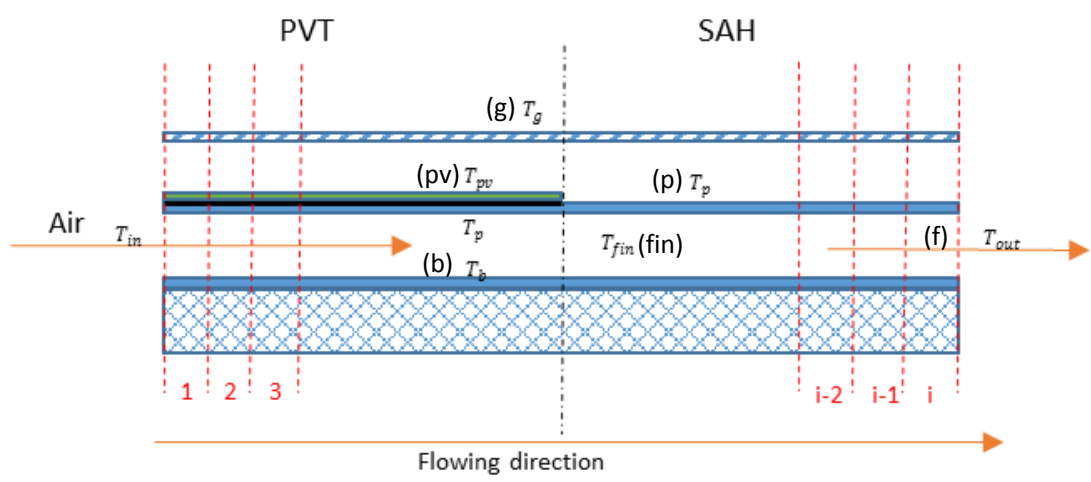

Figure 2 Discretisation of control volumes along the length of PVT-SAH system.

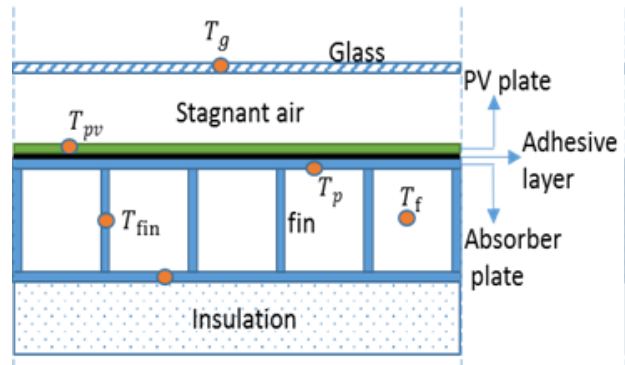

(a) PVT

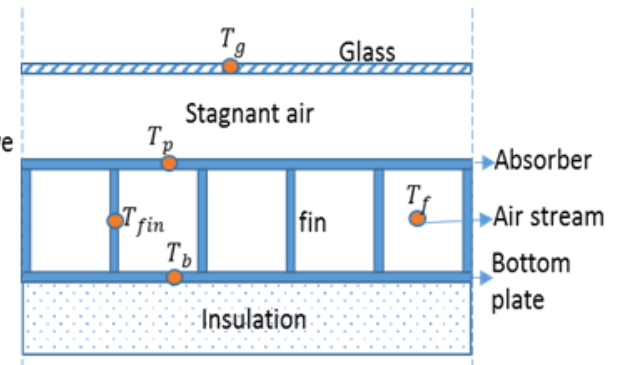

(b) SAH

Figure 3 Cross section views showing the various components of PVT and SAH and the temperatures used in the governing equations.

\subsection{Energy balances for PVT and SAH}

As shown in Figure 2, the PVT-SAH system is divided into a finite number of equally sized control volumes along the air flow direction. A generic energy balance for each control volume can be described by Eq. (1).

$Q_{\text {storage }}=Q_{\text {net radiation }}+Q_{\text {net convection }}+Q_{\text {net conduction }}$

\subsubsection{Energy balance equations for PVT}

\section{$\underline{\text { Top glass (node ' } g \text { ') }}$}

The energy balance equation for the top glazing layer (node ' $g$ ') can be represented by the following partial differential expression.

$$
\begin{aligned}
& A C_{g} M_{g} \frac{\partial T_{g, i}}{\partial t}=\alpha_{g} I_{t} A+h_{n c} A\left(T_{p v, i}-T_{g, i}\right)+h_{r, p v-g} A\left(T_{p v, i}-T_{g, i}\right)+ \\
& h_{w} A\left(T_{a m b}-T_{g, i}\right)+h_{r, g-s k y} A\left(T_{s k y}-T_{g, i}\right)
\end{aligned}
$$


The left hand side term represents the heat storage rate of the glazing layer, while the terms on the right hand side include the fraction of incident solar radiation absorbed by the glass, the natural convection heat exchange and the long wave radiation heat exchange between the PV plate and the glass, the convection loss/gain to ambient air, and the long wave radiation heat exchange between the glass and the sky.

The differential term on the left hand side of Eq. (2) is replaced by a forward difference expression in terms of time. The explicit form of the energy balance for a time step $t$ can then be written as in Eq. (3), in which the time-dependent terms on the right hand side (i.e. heat transfer coefficients, nodal temperatures and solar radiation intensity) are evaluated at the present time step $t$. A discussion on the relationships used for determining the convective and radiative heat transfer coefficients are given in Table 7 in Appendix A. A fully implicit expression of the same energy balance equation as Eq. (2) can be easily obtained by using the values of the future time step $(\mathrm{t}+\Delta \mathrm{t})$ on the right hand side.

$$
\begin{aligned}
& \mathrm{A} C_{g} M_{g}\left[\frac{T_{g, i}^{t+\Delta t}-T_{g, i}^{t}}{\Delta t}\right]=\alpha_{g} I_{t}^{t} A+h_{n c}^{t} A\left(T_{p v, i}^{t}-T_{g, i}^{t}\right)+h_{r, p v-g}^{t} A\left(T_{p v, i}^{t}-T_{g, i}^{t}\right)+ \\
& h_{w}^{t} A\left(T_{a m b}^{t}-T_{g, i}^{t}\right)+h_{r, g-s k y}^{t} A\left(T_{s k y}^{t}-T_{g, i}^{t}\right)
\end{aligned}
$$

When multiplying the explicit expression by a factor of $\gamma(0 \leq \gamma \leq 1)$, the implicit form by a factor of $(1-\gamma)$, and adding them together, the following flexible expression can be derived.

$$
\begin{aligned}
& {\left[C_{g} M_{g}+(1-\gamma) \Delta t\left(h_{n c}^{t+\Delta t}+h_{r, p v-g}^{t+\Delta t}+h_{w}^{t+\Delta t}+h_{r, g-s k y}^{t+\Delta t}\right)\right] T_{g, i}^{t+\Delta t}+[(\gamma-} \\
& \left.1) \Delta t\left(h_{n c}^{t+\Delta t}+h_{r, p v-g}^{t+\Delta t}\right)\right] T_{p v, i}^{t+\Delta t}=\left[C_{g} M_{g}-\gamma \Delta t\left(h_{n c}^{t}+h_{r, p v-g}^{t}+h_{w}^{t}+\right.\right. \\
& \left.\left.h_{r, g-s k y}^{t}\right)\right] T_{g, i}^{t}+\left[\gamma \Delta t\left(h_{n c}^{t}+h_{r, p v-g}^{t}\right)\right] T_{p v, i}^{t}+ \\
& \gamma \Delta t\left[\alpha_{g} I_{t}^{t}+h_{w}^{t} T_{a m b}^{t}+h_{r, g-s k y}^{t} T_{s k y}^{t}\right]+(1-\gamma) \Delta t\left[\alpha_{g} I_{t}^{t+\Delta t}+h_{w}^{t+\Delta t} T_{a m b}^{t+\Delta t}+\right. \\
& \left.h_{r, g-s k y}^{t+\Delta t} T_{s k y}^{t+\Delta t}\right]
\end{aligned}
$$


The combined equation provides a solution that can overcome the disadvantage of the explicit equation with regard to being restricted on the size of time step and space step for solution convergence, but also improves the accuracy level of the fully implicit equation. The parameter $\gamma$ determines the weighting percentage of the explicit part in the resulting energy balance equation. In this study, the same weight was used for both implicit and explicit relations $(\gamma=0.5)$ as default, which is also known as the numerically stable Crank-Nicolson scheme.

The transformation and rearrangement of the governing equations for the other PVT components follow the same process as for the glass cover.

\section{PV plate (node 'pv')}

The energy balance equation for the PV plate (node 'PV') can be represented by Eq.

$\mathrm{A} C_{p v} M_{p v} \frac{\partial T_{p v, i}}{\partial t}=A \operatorname{IAM}\left(\tau_{g} \alpha_{p v}\right)_{n} I_{t}\left(1-\eta_{p v}\right)-A U_{t, p v}\left(T_{p v, i}-T_{a m b}\right)-$

$\mathrm{A} h_{p v-p}\left(T_{p v, i}-T_{p, i}\right)$

The left hand side term of Eq. (5) includes the accumulated energy stored in the PV plate while the right hand side terms represent the solar radiation absorbed by the PV layer minus the fraction of this absorbed radiation that is converted into electricity, the heat loss from the top of the collector (which include convection and radiation heat exchange) and the heat conduction between the PV lamination and the absorber plates. The term of IAM is the incidence angle modifier which is used to account for the offnormal solar radiation effect.

\section{Absorber plate (node 'p')}

The energy balance equation for the absorber plate (node ' $p$ ') is shown in Eq. (6). 


$$
\begin{aligned}
& \mathrm{A} C_{p} M_{p} \frac{\partial T_{p, i}}{\partial t}=A h_{p v-p}\left(T_{p v, i}-T_{p, i}\right)-A h_{c, p-f}\left(T_{p, i}-T_{f, i}\right)-A h_{r, p-b}\left(T_{p, i}-\right. \\
& \left.T_{b, i}\right)-A_{c s} K_{f i n} \frac{\left(T_{p, i}-T_{f i n, i}\right)}{\frac{1}{2} H_{f i n}}
\end{aligned}
$$

The right hand side terms include the conduction flux between the PV plate and the absorber plate, the convection flux to the air that flows within the PVT channels, the long wave radiation exchange with the bottom plate and the conduction heat transfer to the fins. The long wave heat exchange with the fins is considered as negligible in this model.

\section{$\underline{\text { Fins (node 'fin') }}$}

The generic energy balance equation for fins is shown in Eq. (7).

$A_{\text {fin }} C_{f i n} M_{f i n} \frac{\partial T_{f i n, i}}{\partial t}=$

$A_{c S} K_{f i n} \frac{\left(T_{p, i}-T_{f i n, i}\right)}{\frac{1}{2} H_{f i n}}-A_{c s} K_{f i n} \frac{\left(T_{f i n, i}-T_{b, i}\right)}{\frac{1}{2} H_{f i n}}-2 A_{f i n} h_{c, f i n-f}\left(T_{f i n, i}-T_{f, i}\right)$

The right hand side terms of Eq. (7) represent the conduction heat transfer from the absorber plate to the fins, the conduction heat transfer from the fins to the bottom plate and the convection flux from the fin surface to the flowing air.

\section{$\underline{\text { Air stream (node ' } f \text { ') }}$}

The energy balance equation for the air flowing through the air channel (node ' $\mathrm{f}$ ') is given by Eq. (8), in which the average control volume air temperature $\left(T_{f, i}\right)$ is defined by Eq. (9) and the derivative of average control volume air temperature over the length is given by Eq. (10).

$$
\begin{aligned}
& C_{f} \rho_{f} \Delta x\left(W H_{f i n}\right) \frac{\partial T_{f, i}}{\partial t}+C_{f} \dot{M}_{f} \Delta x \frac{\partial T_{f, i}}{\partial x}=\mathrm{A} h_{c, p-f}\left(T_{p, i}-T_{f, i}\right)+A h_{c, b-f}\left(T_{b, i}-\right. \\
& \left.T_{f, i}\right)+2 A_{f i n} h_{c, f i n-f}\left(T_{f i n, i}-T_{f, i}\right) \\
& T_{f, i}=\frac{T_{f, \text { in }, i}+T_{f, \text { out }, i}}{2}
\end{aligned}
$$


$\frac{\partial T_{f, i}}{\partial x}=\frac{T_{f, o u t}-T_{f, i n}}{\Delta x}$

In Eq. (8), the energy storage in the control volume and fluid temperature gradient along the flow direction is equal to the sum of the convection heat transfer from the absorber plate to fluid air, the convection heat transfer between the bottom plate and fluid air, and the convection heat transfer from fins to fluid air.

\section{$\underline{\text { Bottom plate (node ' } b \text { ') }}$}

The energy balance at the bottom plate (Eq. (11)) accounts for the conduction gains/losses from the fins to the bottom plate, the long wave radiation heat transfer between the absorber and the bottom plate, the convection heat flux from the bottom plate to the flowing air and a combined term of the conduction heat transfer through the insulation layer at the back (bottom) of the system with the convection exchanges at the back of the system.

$$
\begin{aligned}
& \mathrm{A} C_{b} M_{b} \frac{\partial T_{b, i}}{\partial t}=A_{c s} K_{f i n} \frac{\left(T_{f i n, i}-T_{b, i}\right)}{\frac{1}{2} H_{f i n}}+A h_{r, p-b}\left(T_{p, i}-T_{b, i}\right)+A h_{c, b-f}\left(T_{f, i}-T_{b, i}\right)- \\
& A U_{b}\left(T_{b, i}-T_{a m b}\right)
\end{aligned}
$$

\subsubsection{Energy balance equations for SAH}

The development of the energy balance equations for SAH is similar to PVT, but there is no PV panel attached onto the absorber layer (see Figure 3 (b)). Therefore, the same energy balance equations as for PVT are used for the glass cover, the fin, the air stream and the bottom plate. However, the heat fluxes for the absorber plate of the SAH are different from that of PVT, and the energy balance equation is given by Eq.

$$
\begin{aligned}
& \mathrm{A} C_{p} M_{p} \frac{\partial T_{p, i}}{\partial t}=A \operatorname{IAM}\left(\tau_{g} \alpha_{p}\right)_{n} I_{t}-A U_{t, p}\left(T_{p, i}-T_{a m b}\right)-A h_{c, p-f}\left(T_{p, i}-T_{f, i}\right)- \\
& A h_{r, p-b}\left(T_{p, i}-T_{b, i}\right)-A_{c s} K_{f i n} \frac{\left(T_{p, i}-T_{f i n, i}\right)}{\frac{1}{2} H_{f i n}}
\end{aligned}
$$


The right hand side of Eq. (12) includes the absorbed incident shortwave solar radiation on the collector, the overall heat loss from the absorber plate to the ambient environment, the convection heat transfer to the flowing air in the air channel, the long wave heat exchanges between the absorber and the bottom plates, and finally the conduction heat flux between the absorber and the fin.

\subsection{Numerical solution procedure}

To derive the self and cross-coupling coefficients, each of the energy balance equation presented in Section 3.3 is written into a uniform format and the whole set of equations are solved in matrices that are of the following generic form:

$\mathbf{E} T^{t+\Delta t}=\mathbf{F} T^{t}+\mathbf{G}=\mathbf{Q}$

where $T$ is a column matrix of the nodal temperatures with six elements for PVT and five elements for $\mathrm{SAH}$, and $E$ and $F$ are the matrices containing temperature and nontemperature dependent coefficients for the future and present time steps respectively, $\mathrm{G}$ contains the terms from the energy balance equation of each component that are known at the current time step (weather boundary conditions, etc.). As $T^{t}$ includes all the already solved nodal temperatures at the present time step, the two terms on the right hand side of Eq. (13) can be combined into the matrix $Q$. Based on the above principles, the expanded form of the matrix for PVT and SAH is demonstrated below. The detailed expressions of the coefficients appearing in Eq. (14) and Eq. (15) are summarised in Appendix B.

For PVT:

$$
\left[\begin{array}{cccccc}
E_{1,1} & E_{1,2} & 0 & 0 & 0 & 0 \\
0 & E_{2,2} & E_{2,3} & 0 & 0 & 0 \\
0 & E_{3,2} & E_{3,3} & E_{3,4} & E_{3,5} & E_{3,6} \\
0 & 0 & E_{4,3} & E_{4,4} & E_{4,5} & E_{4,6} \\
0 & 0 & E_{5,3} & E_{5,4} & E_{5,5} & E_{5,6} \\
0 & 0 & E_{6,3} & E_{6,4} & E_{6,5} & E_{6,6}
\end{array}\right] \times\left[\begin{array}{c}
T_{g}^{t+\Delta t} \\
T_{p v}^{t+\Delta t} \\
T_{p}^{t+\Delta t} \\
T_{f i n}^{t+\Delta t} \\
T_{f}^{t+\Delta t} \\
T_{b}^{t+\Delta t}
\end{array}\right]=\left[\begin{array}{c}
\mathrm{Q}_{1} \\
\mathrm{Q}_{2} \\
\mathrm{Q}_{3} \\
\mathrm{Q}_{4} \\
\mathrm{Q}_{5} \\
Q_{6}
\end{array}\right]
$$


For SAH:

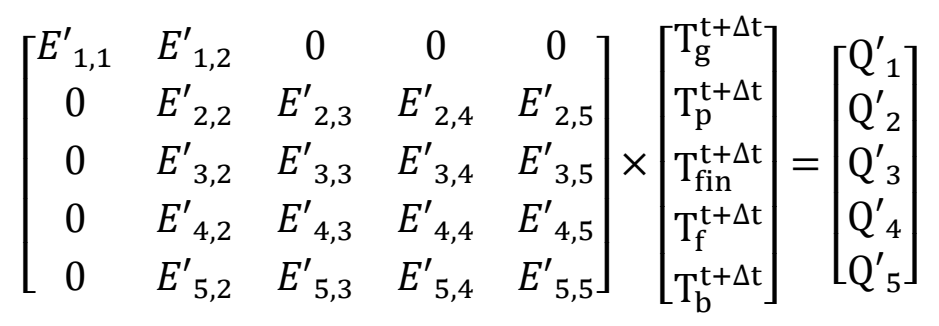

A flow diagram of the solution procedure is shown in Figure 4. Eqs. (19) - (27) in the diagram used to calculate the heat transfer coefficients are listed in Appendix A.

The solution procedure developed to solve the discretised dynamic model in terms of time and length is summarised below:

1. At the first time step of the simulation, the initial present time step temperatures are assumed and assigned to all finite control volumes of the hybrid PVT-SAH. These initial temperatures are employed to calculate the temperature dependent heat transfer coefficients at the present time step. Other required non-temperature dependent matrix coefficients are also computed according to the boundary excitation input at the present time step.

2. A guess is also made on the future-time temperatures of the PVT-SAH components $\left(5^{\circ} \mathrm{C}\right.$ is added by default to the temperatures of the present time step). The coefficients that were calculated in step 1 are calculated again based on the assumed temperature and boundary excitation inputs for the future time step.

3. The elements of matrix $\mathrm{Q}^{\mathrm{Q}}$ ' in Eq. (14)/Eq. (15) are then calculated from the above obtained (from steps 1 and 2) present and future time heat transfer coefficients and corresponding boundary excitation terms.

4. The calculated future-time heat transfer coefficients in step 2 are substituted into the elements of global matrix E/E' in Eq. (14)/Eq. (15). Through matrix calculation, a set of new future-time node temperatures is obtained. 


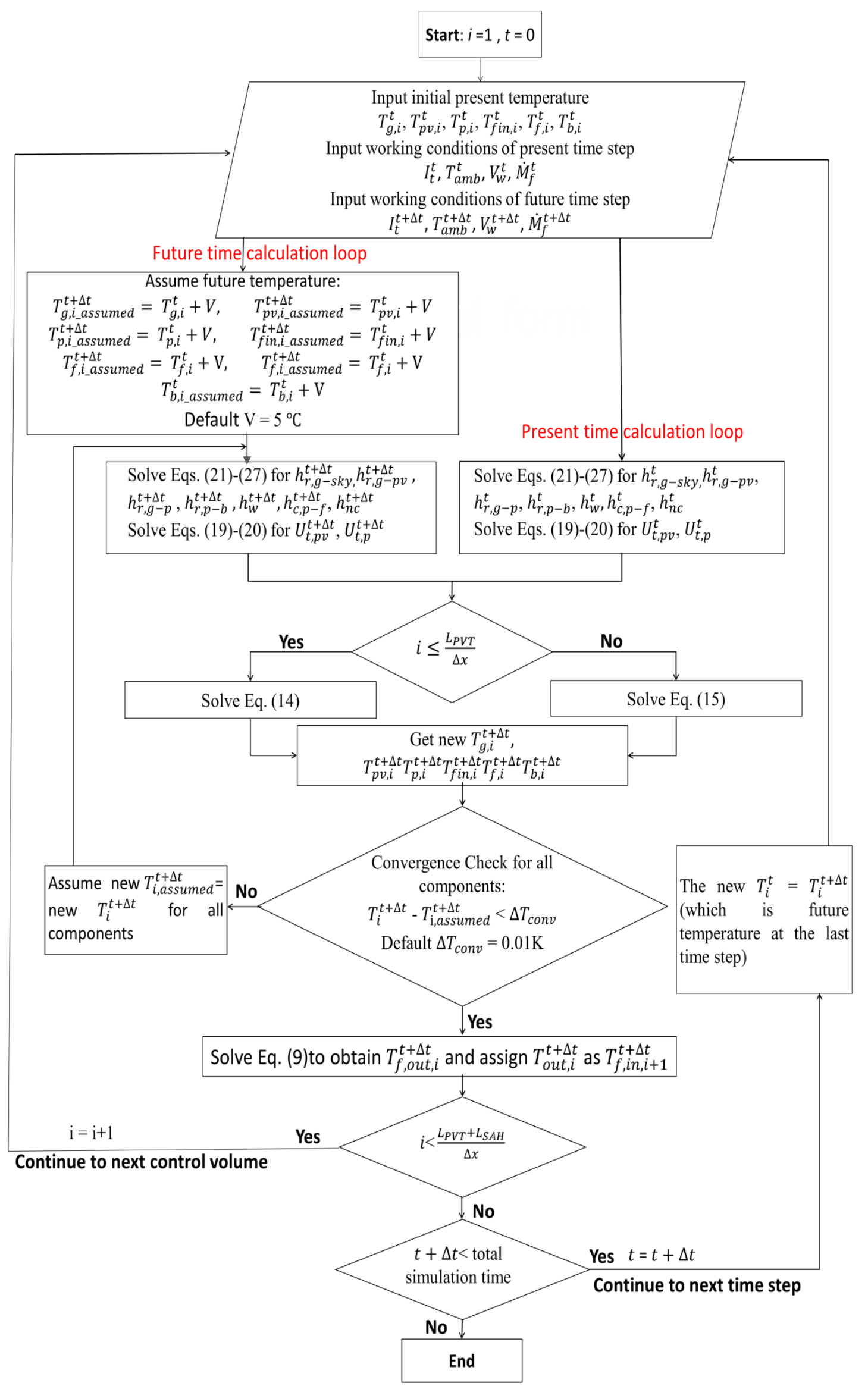

Figure 4. Workflow diagram of solution procedures of the dynamic model

5. The new obtained future-time temperatures are compared with the assumed future 
temperatures (from step 2). The iterative process will be repeated until the difference between the two consecutive future-step temperatures is less than 0.01 $\mathrm{K}$ (default convergence criteria used).

6. By setting the inlet air temperature the same as the outlet air temperature of the last control volume and processing steps 1 to 5, the nodal temperatures of the next neighbouring control volume can be obtained. This iterative process is repeated up to the last control volume along the length of PVT-SAH system after which the nodal temperatures for all control volumes are obtained for the first time step. The above computed nodal temperatures for the first time step are then used as the present time step temperatures for the next time step.

7. The solution process continues with the next time step by repeating steps 1 to 6 until the last simulation time step.

\section{Model validation}

\subsection{Validation using the data collected from an experimental test facility}

\subsubsection{Description of the test rig}

A PVT test rig (Figure 5) located on the roof of the Sustainable Building Research Centre (SBRC), at the University of Wollongong in Australia is used to validate the dynamic model under real operational conditions. The test rig has dimensions of $3 \mathrm{~m}$ length and $3 \mathrm{~m}$ width. In the test, the photovoltaic system with a length of $1.7 \mathrm{~m}$ is attached onto the PVT test rig, while the remaining part of the test rig is used to mimic a SAH (Figure 6). The photovoltaic system is characterized as thin-film amorphous silicon product with electrical efficiency of $11.2 \%$ under standard testing conditions $\left(25^{\circ} \mathrm{C}\right)$ and temperature coefficient of $-0.23 \% /{ }^{\circ} \mathrm{C}$. The azimuth angle and tilt angle of PVT test rig are adjustable so that the performance can be evaluated under different relative positions to the sun. During the testing period, the 
azimuth angle and tilt angle were adjusted to be $0^{\circ}$ (north facing) and $22.5^{\circ}$ respectively. A galvanized steel constructed manifold is installed at the inlet to ensure the air is evenly distributed to all air flow ducts. Over the width of the test rig, there are seven equally sized air channels (Figure 6). The metal slats that are separating the air channels were considered as longitudinal fins in this study. However, one limitation of this test rig is that it does not have a glass cover on the top. For validation purposes, the model was adapted accordingly by removing the heat transfer equation for the top glass (Eq. (2)). As a result, in the final matrix equations of Eqs. (14) and (15), the coefficients of $E_{1,1}, E_{1,2}$ and $Q_{1}$ for glass cover are set as zero and the top heat loss coefficient $U_{t, p v}$ in Eq. (14) and $U_{t, p}$ in Eq. (15) were hereby calculated as the sum of the heat transfer coefficients for the long wave radiation heat exchange (PV/absorber plate and sky) and the convection heat exchange between the PV plate/absorber plate and ambient air (i.e. $h_{r, p v-s k y}+h_{w}$, $\left.h_{r, p-s k y}+h_{w}\right)$. Some major input parameters for the model are listed in Table 1.

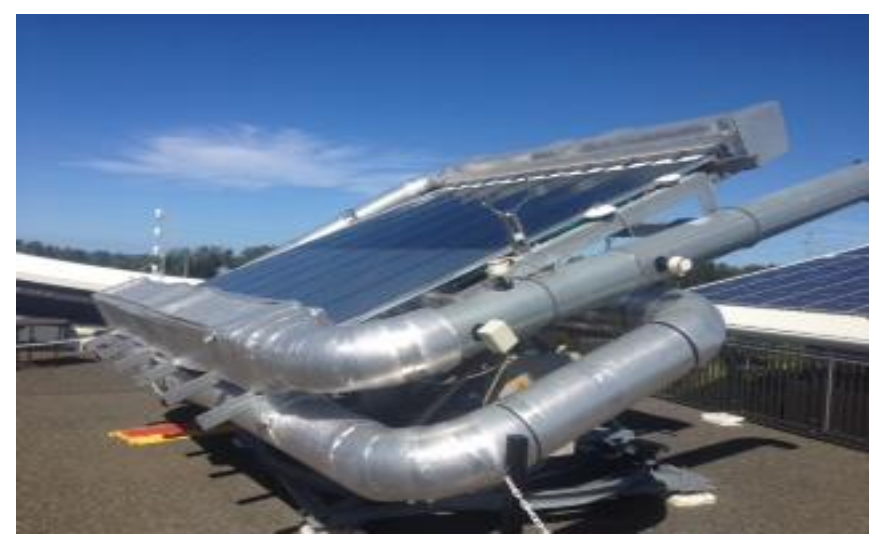

Figure 5. The test rig used to validate the dynamic model of PVT-SAH. 

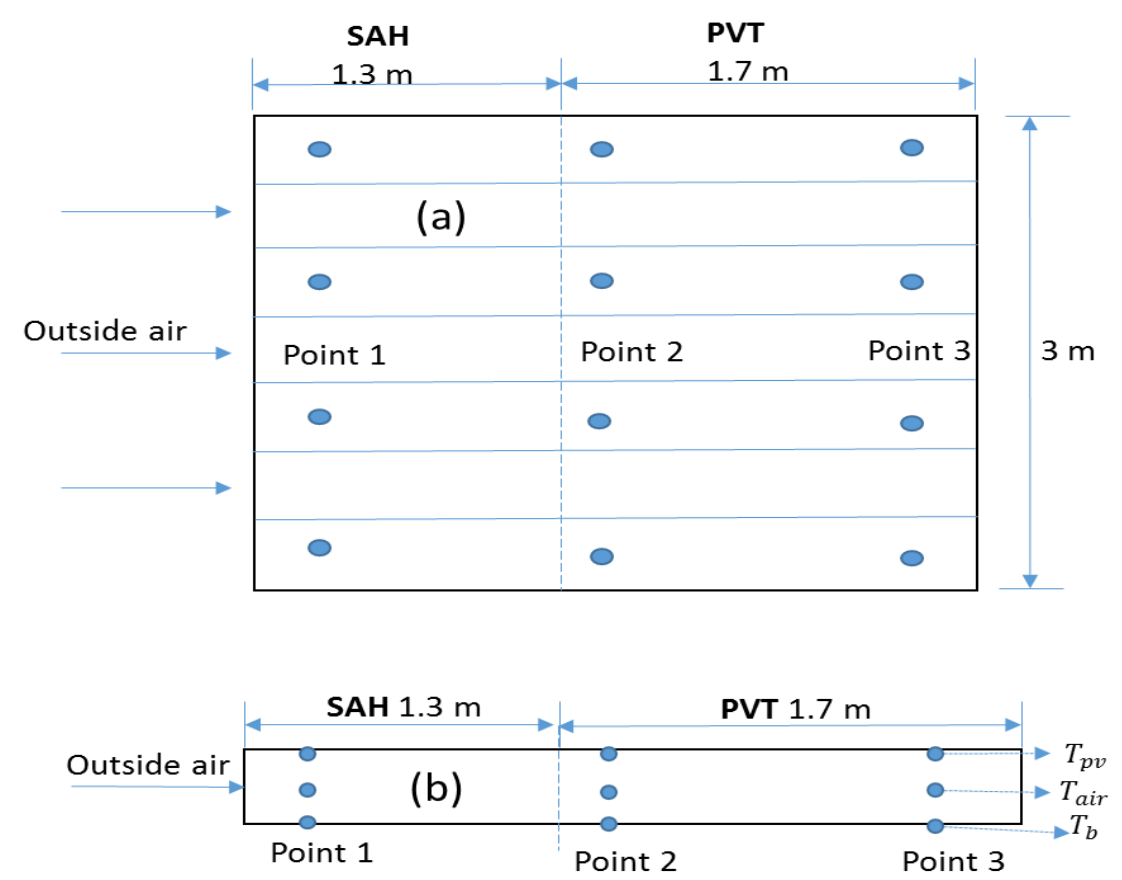

Figure 6. Front view (a) and cross section view (b) of PVT-SAH test rig used for model validation; the blue dots represent the temperature measurement points.

Table 1. Major component properties of the test rig

\begin{tabular}{ll|ll}
\hline Parameter & Value & Parameter & \multicolumn{1}{c}{ Value } \\
\hline Mass per & square & $M_{p v}=7 \mathrm{~kg} / \mathrm{m}^{2}$ & $C_{p}=C_{f i n}=C_{b}=$ \\
meters & $M_{p}=M_{f i n}=M_{b}=7.8 \mathrm{~kg} / \mathrm{m}^{2}$ & Heat capacity & $0.48 \mathrm{~kJ} / \mathrm{kg} . \mathrm{K} \mathrm{[55]}$ \\
& & & $C_{p v}=0.75 \mathrm{~kJ} / \mathrm{kg} \cdot \mathrm{K}$ \\
& & Thermal & $K_{p}=K_{\text {fin }}=162 \mathrm{~kJ} / \mathrm{hr} \cdot \mathrm{m} \cdot \mathrm{K}$ \\
Emissivity & $\varepsilon_{p v}=0.90$ & conductivity & {$[55]$} \\
& $\varepsilon_{p}=\varepsilon_{b}=0.7$ & & $K_{\text {insu }}=0.144 \mathrm{~kJ} / \mathrm{hr} \cdot \mathrm{m} \cdot \mathrm{K}[55]$ \\
Absorption & $\alpha_{p v}=0.9$ & $\Delta y_{\text {fin }}=0.001 \mathrm{~m}$ \\
& $\alpha_{p}=0.75$ & Thickness & $\Delta y_{\text {insu }}=0.01 \mathrm{~m}$ \\
& & & \\
\hline
\end{tabular}

\subsubsection{Instrumentation and methodology}

The measured data was collected with a DT 80 data logger. The instrumentation specifications and the parameters measured for model validation purpose are summarised in Table 2. The temperatures at different positions of the test rig are the most important outputs that were used for the comparison between the model predictions and the measurements. An array of 36 Type-T thermocouples were placed 
in 12 positions (see Figure 6(a)), with 4 positions across the width and 3 positions along the length of the test facility (named as Points 1 to 3 in Figure 6(a)). At each of the 12 locations, 3 thermocouples measured the temperatures of the absorber/PV plate, bottom plate and flowing air (Figure 6(b)). A Pitot tube was employed to measure the pressure drop across the length of the test rig in order to derive the volumetric air flow rate. The volumetric air flow rate, the inlet air temperature at point 1 (Figure 7) and the dynamic weather conditions (Figure 8) are used as inputs to predict the component temperatures at different locations of the test rig.

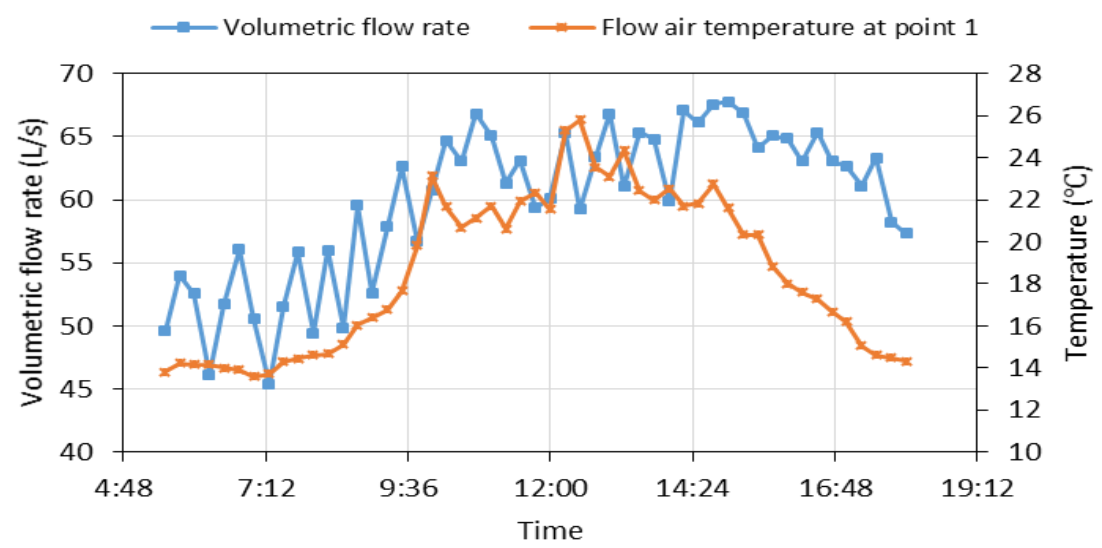

Figure 7. Variation of volumetric flow rate and inlet air temperature at point 1 during the testing period.

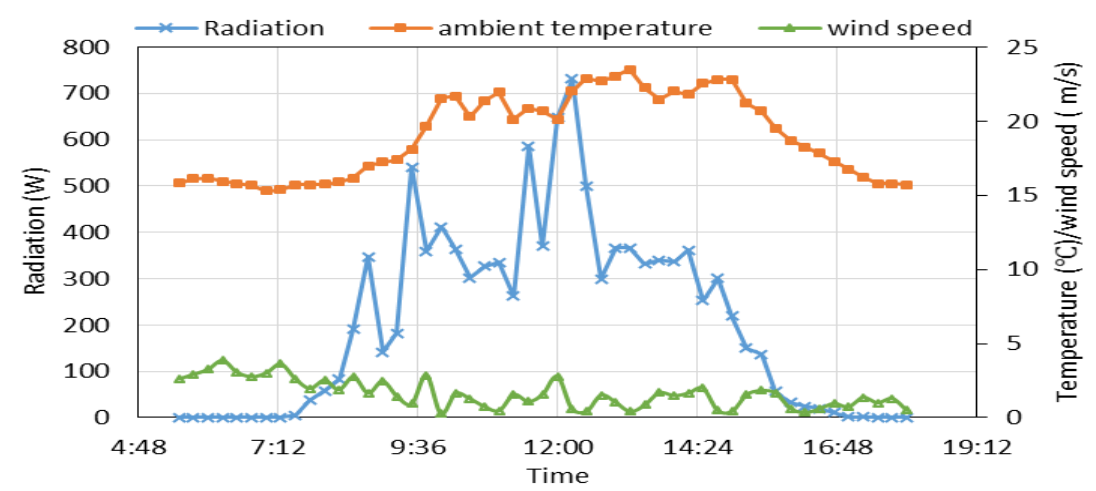

Figure 8. Measured solar radiation, ambient air temperature and wind speed for the validation period. 
Table 2 Instrumentation and the parameters measured during the testing

\begin{tabular}{llc}
\hline Instrumentation & Measured parameter & Accuracy \\
\hline Kipp \& Zonen CMP6 Pyranometer & Global solar radiation on PVT-SAH & $\pm 5 \%$ \\
Platinum RTD sensor & Ambient temperature & $\pm 0.03-0.12^{\circ} \mathrm{C}$ \\
Vaisala WMT700 ultrasonic & Wind speed & $\pm 0.1 \mathrm{~m} / \mathrm{s}$ \\
Pitot tube & Pressure drop & $\pm 1 \%$ \\
Type T thermocouples & Temperatures at 12 positions & $\pm 1{ }^{\circ} \mathrm{C}$ \\
\hline
\end{tabular}

\subsubsection{Validation results}

Figures 9 to 11 present the measured and modelled temperatures along the length of the PVT-SAH system. A good agreement between measurements and simulation results is observed. To quantify their differences, the root-mean-square deviation (RMSD) and the normalised relative root mean square deviation (NRMSD) are calculated. The RMSD of all measurement points were below $1.3^{\circ} \mathrm{C}$, with NRMSD of 5.5\% (Table 3). The RMSD and NRMSD values of all measurement points along the length of the system are shown in Table 3.
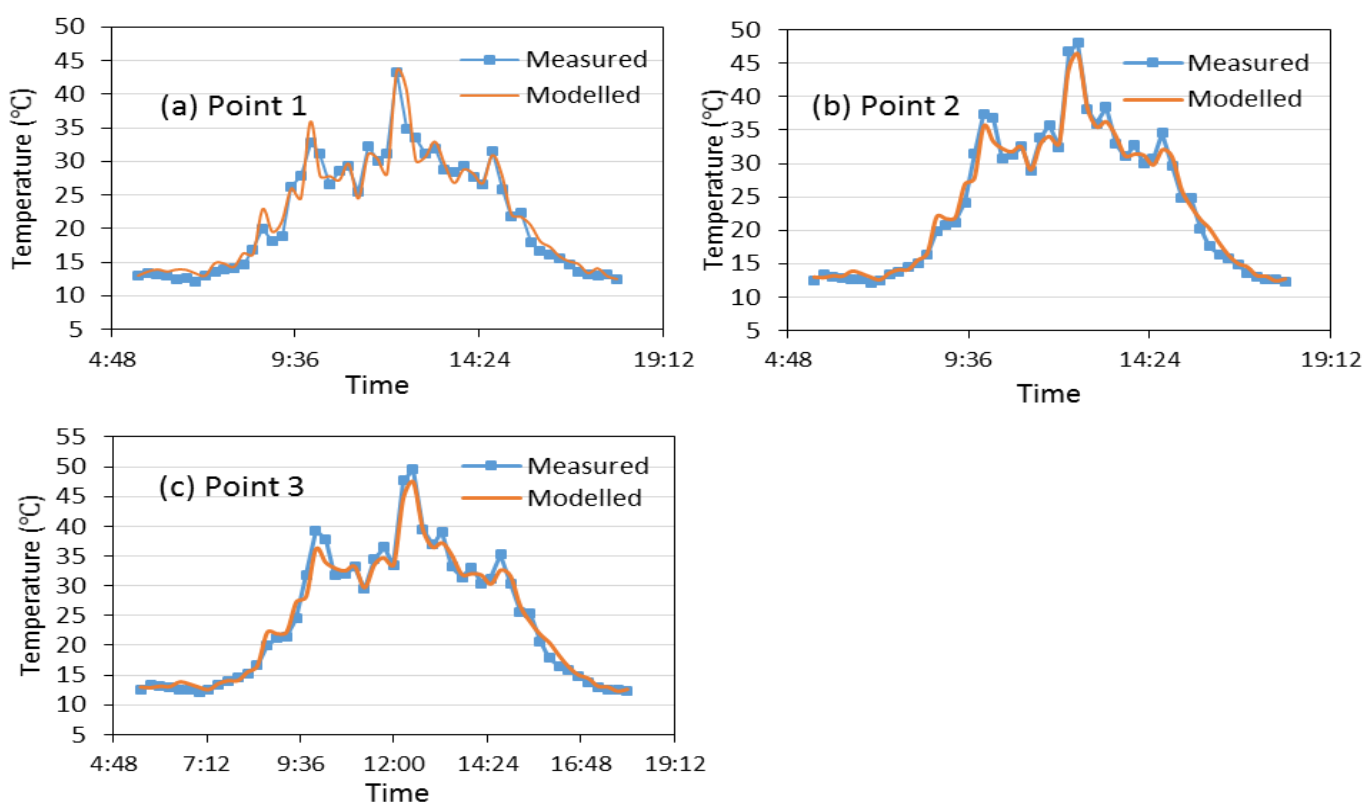

Figure 9. (a), (b), (c) represent the measured and modelled temperatures of the absorber plate at Point 1, PV plate temperatures at Point 2 and Point 3, respectively. 

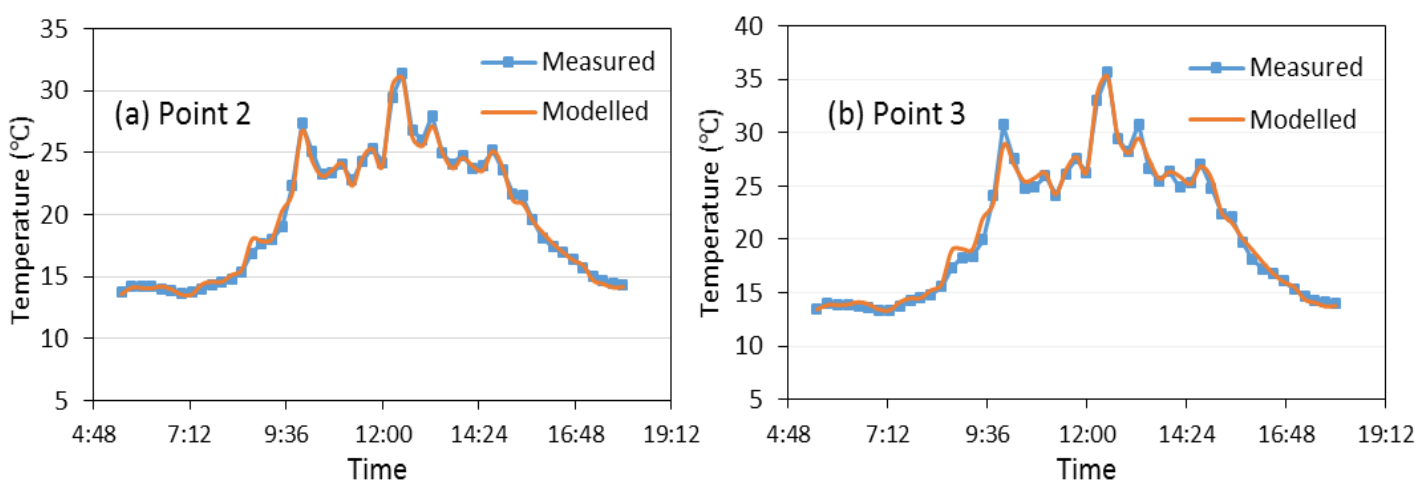

Figure 10. Measured and modelled flowing air temperatures at Point 2 (10a) and Point 3 (10b).
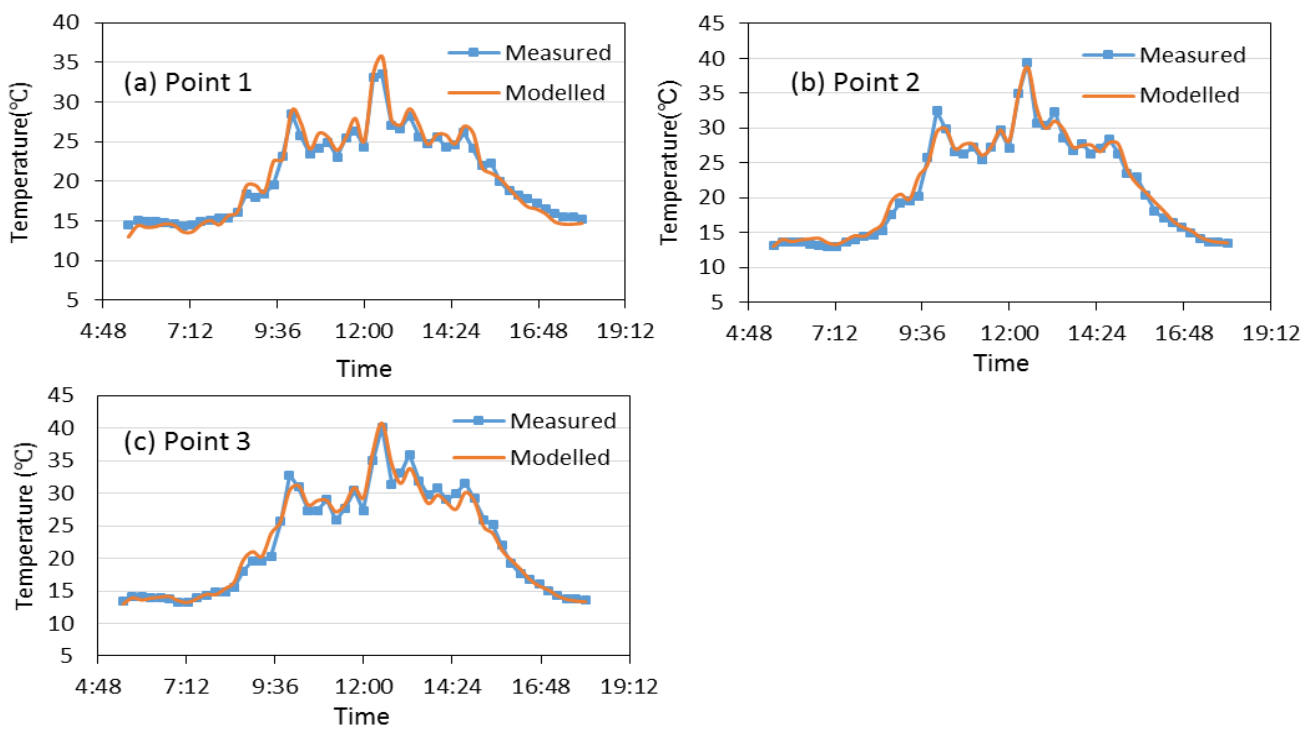

Figure 11. Measured and modelled temperatures of the bottom plate at Point 1(a), Point 2(b) and Point 3(c).

Table 3. Statistical indicators for average deviations between measured and modelled temperature at different positions and for the various PVT-SAH components

\begin{tabular}{llll}
\hline Components & Measurement point & RMSD & NRMSD \\
\hline Absorber plate & Point 1 & $1.3{ }^{\circ} \mathrm{C}$ & $5.5 \%$ \\
PV plate & Point 2 & $1.2{ }^{\circ} \mathrm{C}$ & $4.8 \%$ \\
& Point 3 & $1.2{ }^{\circ} \mathrm{C}$ & $5.3 \%$ \\
\multirow{2}{*}{ Flowing air } & & & \\
& Point 2 & $0.3{ }^{\circ} \mathrm{C}$ & $2.1 \%$ \\
Bottom plate & Point 3 & $0.5{ }^{\circ} \mathrm{C}$ & $2.9 \%$ \\
& Point 1 & $0.9{ }^{\circ} \mathrm{C}$ & $4.6 \%$ \\
& Point 2 & $0.9{ }^{\circ} \mathrm{C}$ & $4.5 \%$ \\
\hline
\end{tabular}


Experimental studies for validating dynamic models are generally difficult in practice since in most cases it is not possible to measure every variable of the energy balance equations. This has been recognised by the recent work undertaken within IEA ECB Annex 58 [56]. For this reason, the dynamic model developed in this study is further validated by comparing with the reference data from the literature.

4.2. Validation by comparing with the reference data

The dynamic model is further validated by comparing the simulation results with the reference data reported by Matrawy [3]. Matrawy [3] presented a steady state model of SAH with fins and for this reason, the dynamic model in this paper is required to be re-configured as 'steady state' by setting the values of the heat capacity and mass per unit area to be negligibly small $\left(0.00001 \mathrm{~kJ} / \mathrm{kg} . \mathrm{K}\right.$ and $0.00001 \mathrm{~kg} / \mathrm{m}^{2}$ were used respectively).

The SAH for this comparison is $6 \mathrm{~m}$ long and $1 \mathrm{~m}$ wide. The channel depth is $0.025 \mathrm{~m}$ and it has 10 fins in total. A daily simulation was performed under the mass flow rate of $300 \mathrm{~kg} / \mathrm{h}$. The outlet air temperature predicted by the dynamic model of this paper is compared with the reference data (Figure 12). It is found that the simulation results

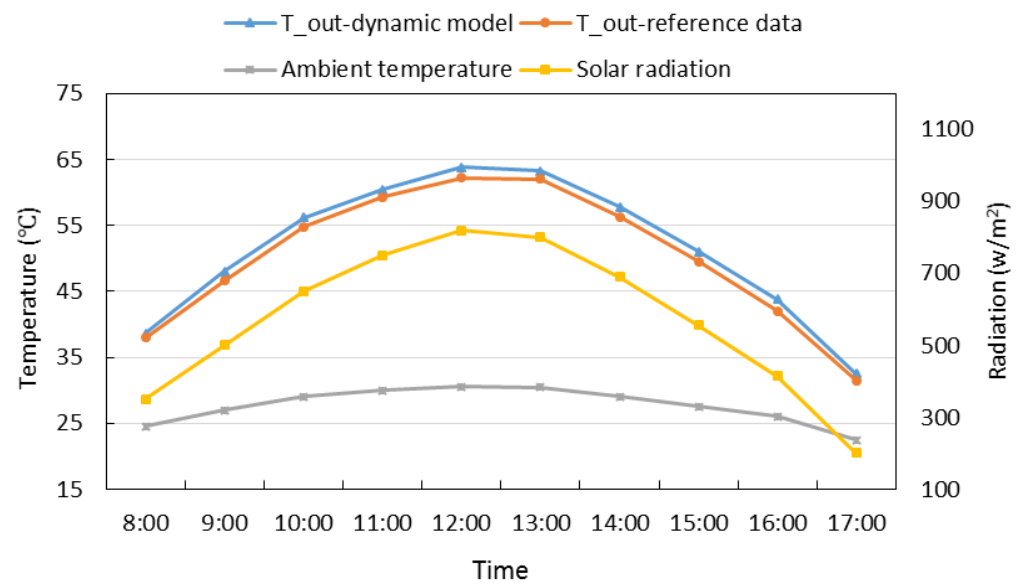

Figure 12. Weather data and outlet air temperature from model predictions and reference data. 
matched well the reference data. The RMSD for the outlet air temperature is $1.15^{\circ} \mathrm{C}$ with NRMSD of $2.27 \%$.

\section{Analysis of dynamic performance of PVT-SAH}

Based on the dynamic model developed, the dynamic nature of PVT-SAH system is tested and investigated through two simulation cases under dynamic working conditions (i.e. change of solar radiation and mass flow rate). A simulation study is also conducted to compare the difference between the dynamic model and its equivalent steady state model.

The major design parameters used for the simulations of the hybrid PVT-SAH are summarised in Table 4.

Table 3. Major input design parameters of integrated PVT-SAH for simulation study

\begin{tabular}{|c|c|c|c|}
\hline Parameter & Value & Parameter & Value \\
\hline Length of PVT & $3 \mathrm{~m}$ & Number of fins & 19 \\
\hline Length of SAH & $3 \mathrm{~m}$ & Fin height & $0.025 \mathrm{~m}$ \\
\hline Width of collector & $1 \mathrm{~m}$ & $\begin{array}{l}\text { Spacing between glass and } \\
\text { absorber }\end{array}$ & $0.025 \mathrm{~m}$ \\
\hline Insulation thickness & $0.05 \mathrm{~m}$ & Number of control volume & 24 \\
\hline $\begin{array}{l}\text { Thermal conductivity } \\
(\mathrm{kJ} / \mathrm{hr} \cdot \mathrm{m} \cdot \mathrm{K})\end{array}$ & $\begin{array}{l}K_{\text {insu }}=0.144 ; \quad K_{p}= \\
K_{\text {fin }}=162 ;\end{array}$ & Emissivity & $\begin{array}{l}\varepsilon_{p v}=\varepsilon_{p}=\varepsilon_{b}=0.9 \\
\varepsilon_{g}=0.88\end{array}$ \\
\hline Absorptance & $\begin{array}{l}\alpha_{p v}=0.85 ; \alpha_{p}=0.9 ; \alpha_{g} \\
=0.01\end{array}$ & $\begin{array}{l}\text { Mass per square meters } \\
\left(\mathrm{kg} / \mathrm{m}^{2}\right)\end{array}$ & $\begin{array}{l}M_{g}=5.4 ; M_{p v}=7 \\
M_{p}=M_{\text {fin }}=M_{b}= \\
5.4\end{array}$ \\
\hline $\begin{array}{l}\text { Specific heat capacity } \\
(\mathrm{kJ} / \mathrm{kg} . \mathrm{K})\end{array}$ & $\begin{array}{l}C_{p}=C_{\text {fin }}=C_{b}=0.48 ; C_{g} \\
=0.79 ; C_{p v}=0.75\end{array}$ & & \\
\hline
\end{tabular}

\subsection{Dynamic response to changes of solar radiation intensity}

The first case shows the effect of changing the incident solar radiation from 1000 to $200 \mathrm{~W} / \mathrm{m}^{2}$ while keeping other relevant operational conditions as constants $\left(\dot{M}_{f}=\right.$ $1000 \mathrm{~kg} / \mathrm{h}, T_{a m b}=25^{\circ} \mathrm{C}, V_{w}=3.4 \mathrm{~m} / \mathrm{s}$ ) on the transient behaviour of the hybrid PVT-SAH system. The resulted Time Constants (TC) of all components varied from 30 to 40 mins (Figure 13 (a)). Figure 13 (b) shows that although the thermal energy transferred to the flowing air started to gradually decrease, the thermal inertia maintained the thermal efficiency for a period of time at levels higher than the 
efficiency noted before the reduction of the solar radiation levels. It is also noted that there is a rapid increase of thermal efficiency to $225 \%$ within the first 5 mins after the
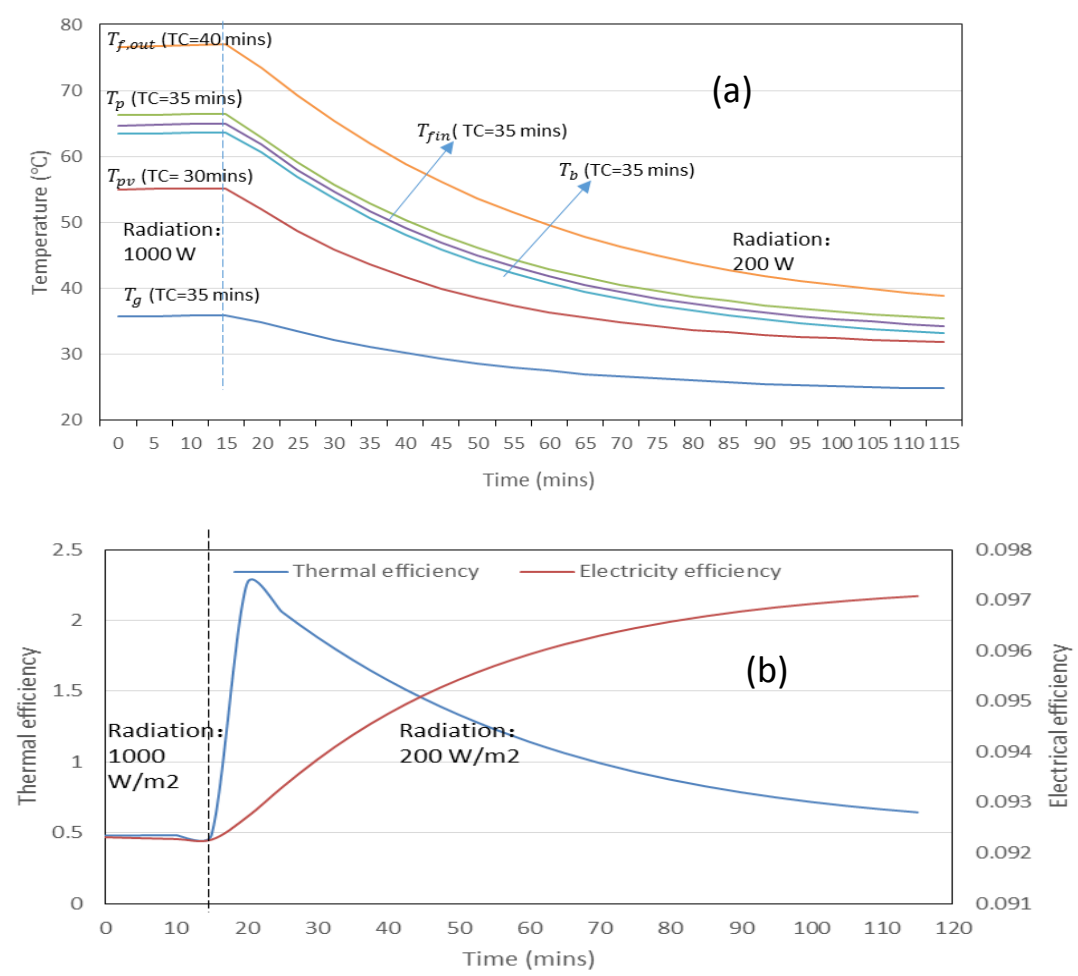

Figure 13. Dynamic response of PVT-SAH system to sudden change of solar radiation from $1000 \mathrm{~W} / \mathrm{m}^{2}$ to $200 \mathrm{~W} / \mathrm{m}^{2}$

variation of solar radiation mostly because the absorber plate maintained high temperatures for a period of time after solar radiation changes (i.e. it still delivers high levels of heat to the flowing air) while the solar radiation used to calculate the thermal efficiency has a low value. In contrast to the gradual decrease of thermal efficiency, the electrical efficiency of PV plate gradual increased with a lower level of radiation. 


\subsection{Dynamic response to change of mass flow rate}

In this case, the mass flow rate is subject to a sudden change from 200 to $500 \mathrm{~kg} / \mathrm{h}$ at simulation time point of 15 mins while keeping the other operational conditions constant $\left(I_{t}=1000 \mathrm{~W} / \mathrm{m}^{2}, T_{a m b}=25^{\circ} \mathrm{C}, V_{w}=3.4 \mathrm{~m} / \mathrm{s}\right)$. After the change of mass flow rate, the temperatures of all components show a gradual decrease moving to a new thermal equilibrium status (Figure 14 (a)). The Time Constants (TC) of the absorber plate, fins and bottom plate are in the order of around 25 mins and the TC for the PV plate, outlet air and glass cover are approximately 15 mins, 20 mins and 30 mins, respectively. It can be seen from Figure 14 (b) that a significant increase of collected thermal energy occurred 5 mins after the sudden change of mass flow rate. The reason for the increase in thermal energy is due to the enhanced convective heat exchange in the air channels. The electricity gains curve illustrated a gradual rise due
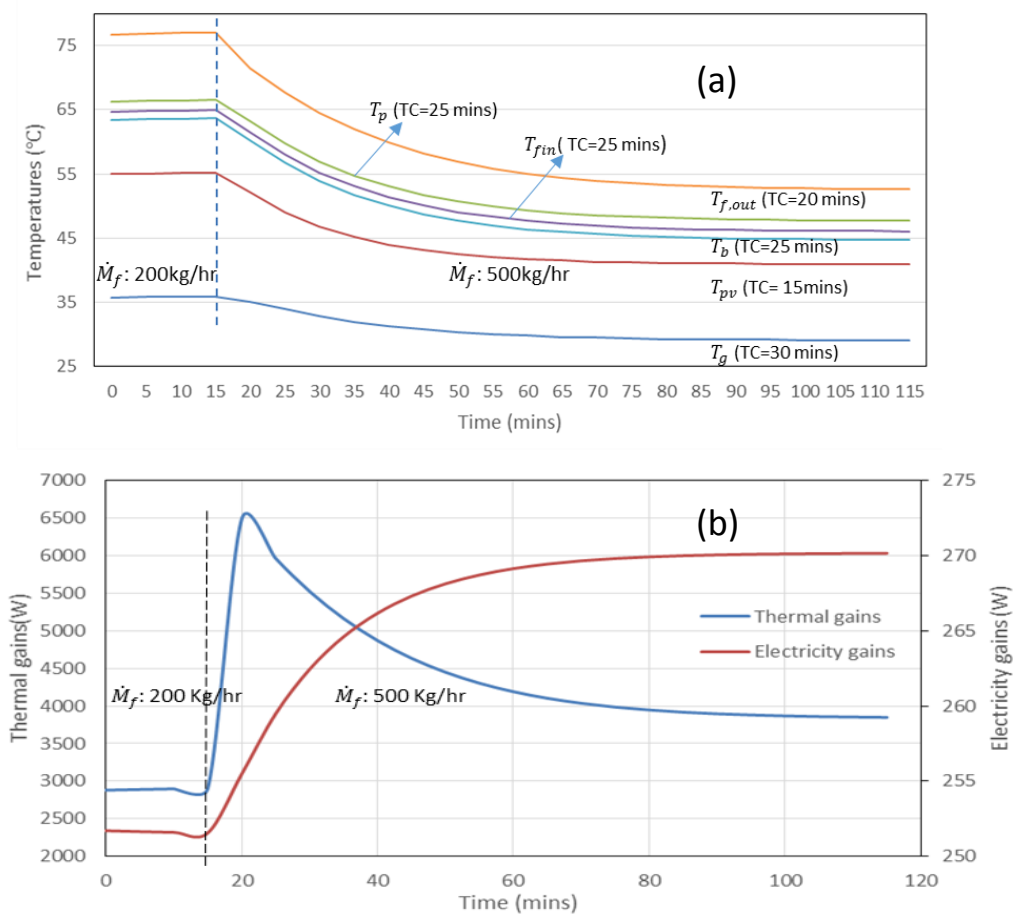

Figure 14. Dynamic response of PVT-SAH system to a sudden change of mass flow rate from 200 to $500 \mathrm{~kg} / \mathrm{h}$ 
to the reduction of the PV plate temperature.

\subsection{Performance comparison between dynamic model and steady state model}

To further elaborate the difference between using a dynamic model for PVT-SAH and an equivalent steady state model, a steady state model is developed by neglecting the heat capacitance terms on the left side of the energy balance equations of the existing dynamic model. An example for the "Top glass" node is shown in Eq. (16).

$0=\partial_{g} I_{t} A+h_{n c} A\left(T_{p v}-T_{g}\right)+h_{r, p v-g} A\left(T_{p v}-T_{g}\right)+h_{w} A\left(T_{a m b}-T_{g}\right)+$

$h_{r, g-s k y} A\left(T_{s k y}-T_{g}\right)$

The solution procedures for the steady-state model are much simpler than those of the dynamic model as no iterative process over time is required and they are not demonstrated here.

The simulations were performed under constant incident solar radiation of $1000 \mathrm{~W} / \mathrm{m}^{2}$ and constant boundary conditions. All construction components were assigned an initial temperature of $25^{\circ} \mathrm{C}$. Figure 15 shows the change of local duct air temperature in all control volumes at different time steps. It is observed that there is 1.5 hours' delay before the local duct air temperature in all control volumes converged to the steady state. As the dynamic model is discretised and solved along space and time, Figure 16 displays the continuous change of local duct air temperature over time and over the length of the system. Meanwhile, the equivalent temperature distribution profile from the steady state model is represented in Figure 17 for comparison purposes. The accumulated thermal energy outputs for both dynamic model and steady state model are obtained by integrating thermal gains over time. The steady state model predicted 15.2 $\mathrm{MJ}$ of thermal gains during the first $80 \mathrm{mins}$ of the simulation while the dynamic model predicted $11.2 \mathrm{MJ}$, which corresponds to a $35 \%$ overestimation by the steady state model. 


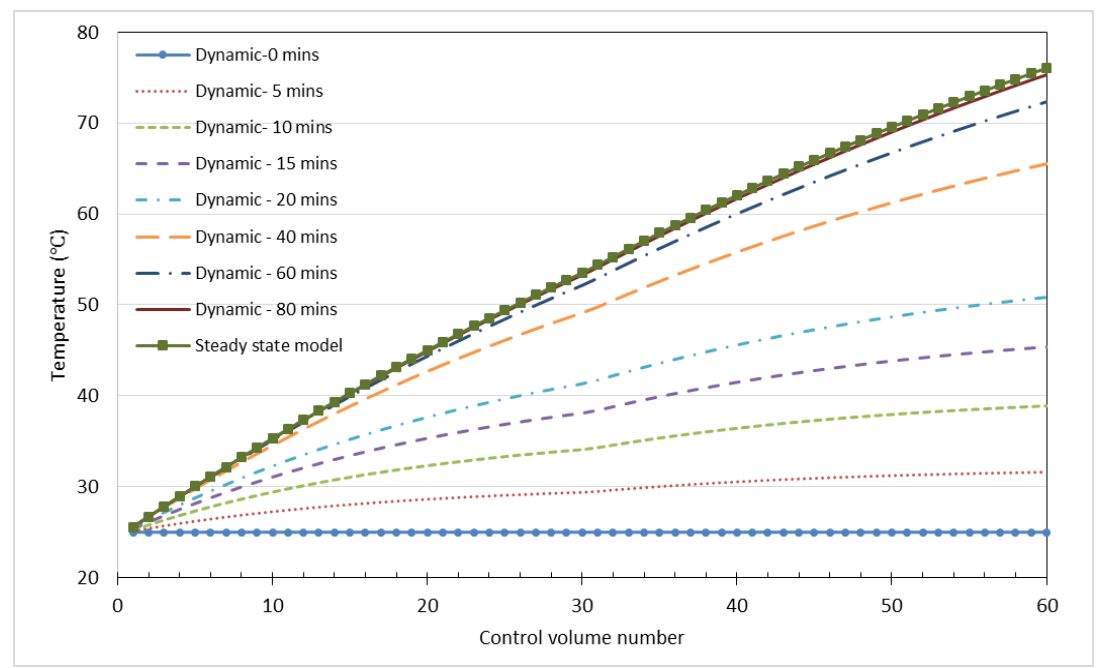

Figure 15. The local duct air temperature in each control volume at different time steps

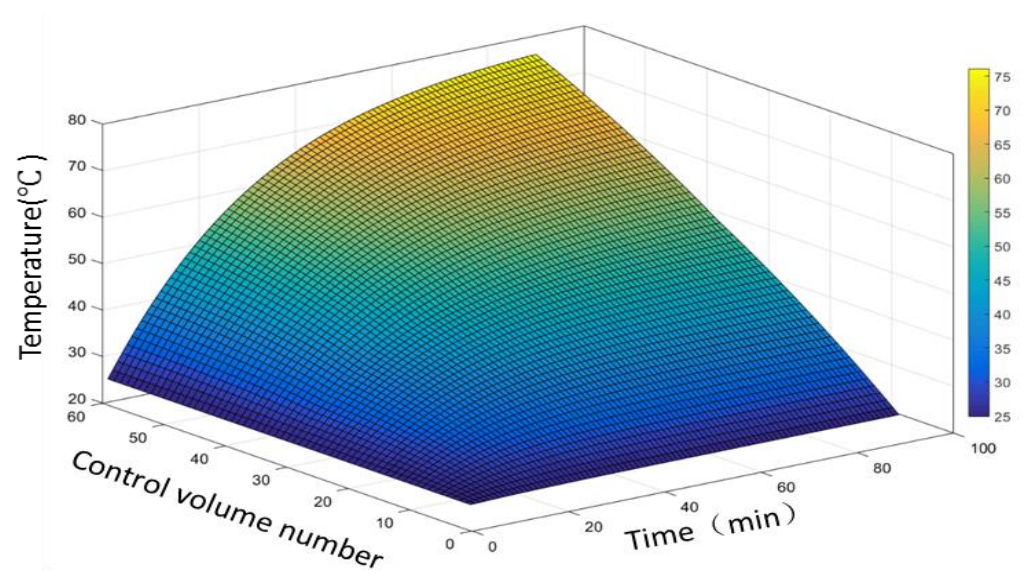

Figure 16. Local duct air temperature over length and time as predicted by the dynamic model

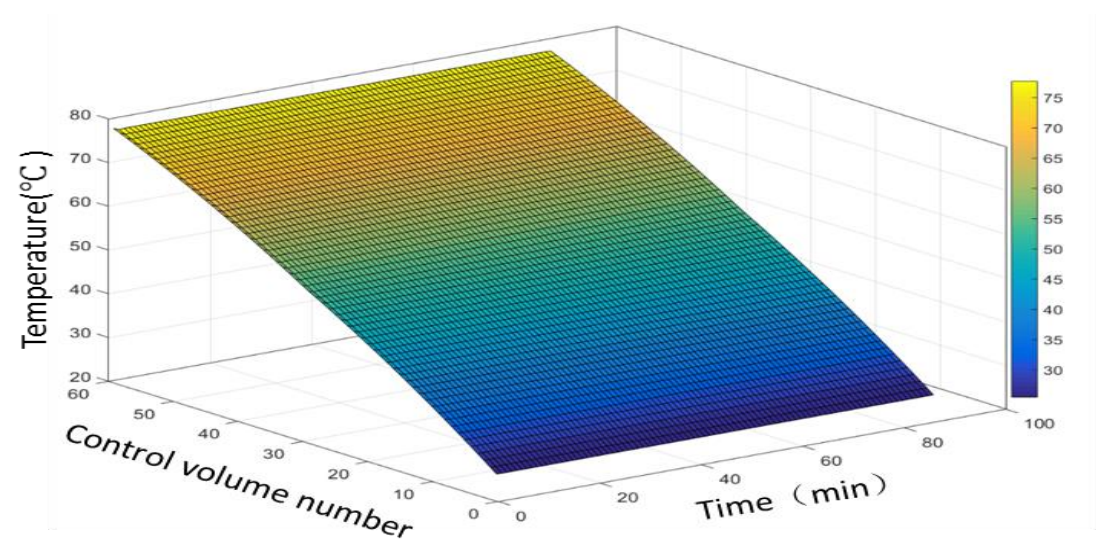

Figure 17. Local duct air temperature over length and time as predicted by the steady state model 
The stability of the dynamic model on the selection of time step and space step is further investigated. The average component temperatures, the outlet air temperature of the last control volume and the thermal and electrical efficiencies were calculated from the model for different space and time step and were listed in Tables 5(a) and 5(b). It is found that the range of variations of results is small, and the maximum relative errors caused by varying both the space step and time step are always less than $2 \%$. The results in Tables $5(\mathrm{a})$ and $5(\mathrm{~b})$ confirm that the dynamic model presented in this paper is numerically stable.

Table 5(a) Comparison of mean component temperature and efficiencies by varying space step (simulations were run with the conditions specified in section 5.2 and mass flow rate of $200 \mathrm{~kg} / \mathrm{h}$ ).

\begin{tabular}{lllllll}
\hline Parameters & \multicolumn{5}{c}{ Space step (length of control volume) } & Max relative \\
\cline { 2 - 6 } & $3 \mathrm{~m}$ & $1.5 \mathrm{~m}$ & $0.6 \mathrm{~m}$ & $0.3 \mathrm{~m}$ & $0.15 \mathrm{~m}$ & error (\%) \\
\hline$T_{g}$ & 35.08 & 35.26 & 35.31 & 35.31 & 35.31 & 0.66 \\
$T_{p v}$ & 54.31 & 54.84 & 54.98 & 55 & 55.01 & 1.29 \\
$T_{p}$ & 65.86 & 66.26 & 66.38 & 66.39 & 66.4 & 0.82 \\
$T_{\text {fin }}$ & 65.41 & 65.82 & 65.93 & 65.95 & 65.95 & 0.83 \\
$T_{b}$ & 65.1 & 65.51 & 65.62 & 65.64 & 65.64 & 0.83 \\
$T_{f, \text { out }}$ & 77.22 & 76.92 & 76.83 & 76.82 & 76.81 & 0.83 \\
$\eta_{\text {ele }}$ & 0.0842 & 0.084 & 0.0839 & 0.0839 & 0.0839 & 0.36 \\
$\eta_{\text {th }}$ & 0.486 & 0.483 & 0.482 & 0.482 & 0.482 & 0.78 \\
\hline
\end{tabular}

Table 5(b) Comparison of mean component temperature and efficiencies by varying time step (simulations were run with the conditions specified in section 5.2 and mass flow rate of $200 \mathrm{~kg} / \mathrm{h}$ ).

\begin{tabular}{cllllll}
\hline Parameters & \multicolumn{5}{c}{ Time step } & $\begin{array}{l}\text { Max relative } \\
\text { error }(\%)\end{array}$ \\
\cline { 2 - 6 } & 15 mins & 9 mins & 6 mins & 3mins & $0.6 \mathrm{mins}$ & 0.83 \\
$T_{g}$ & 35.11 & 35.27 & 35.31 & 35.39 & 35.4 & 0.16 \\
$T_{p v}$ & 55.22 & 55.14 & 55.01 & 55.13 & 55.13 & 0.13 \\
$T_{p}$ & 65.44 & 66.49 & 66.4 & 66.63 & 66.64 & 0.30 \\
$T_{\text {fin }}$ & 65.45 & 65.71 & 65.95 & 66.1 & 66.11 & 1.01 \\
$T_{b}$ & 64.9 & 65.33 & 65.64 & 65.81 & 65.82 & 1.42 \\
$T_{f, \text { out }}$ & 76.13 & 76.56 & 76.81 & 77.12 & 77.13 & 1.31 \\
$\eta_{\text {ele }}$ & 0.0838 & 0.084 & 0.0839 & 0.0839 & 0.0839 & 0.12 \\
$\eta_{\text {th }}$ & 0.475 & 0.481 & 0.482 & 0.485 & 0.485 & 1.98 \\
\hline
\end{tabular}

\section{Influence of fin number and fin height on the performance of PVT-SAH}

The number and height of fins was altered to investigate the effect of these parameters on the performance of the hybrid system. In this case, the fin height is equal to the air channel depth and the weather conditions were kept constant and the same as in section 5.2 with a mass flow rate of $300 \mathrm{~kg} / \mathrm{h}$. The changes of the thermal and 
electrical efficiencies and the pressure drop are plotted in Figure 18 versus different fin heights and different fin numbers. It can be illustrated that both the thermal and electrical efficiencies will be improved by increasing the number of fins and by reducing the fin height. The increase of the system efficiencies when the number of fins is increased is attributed to the larger heat transfer areas. Moreover, when the fin height, and therefore the channel depth, is reduced, the efficiencies increase because of the higher
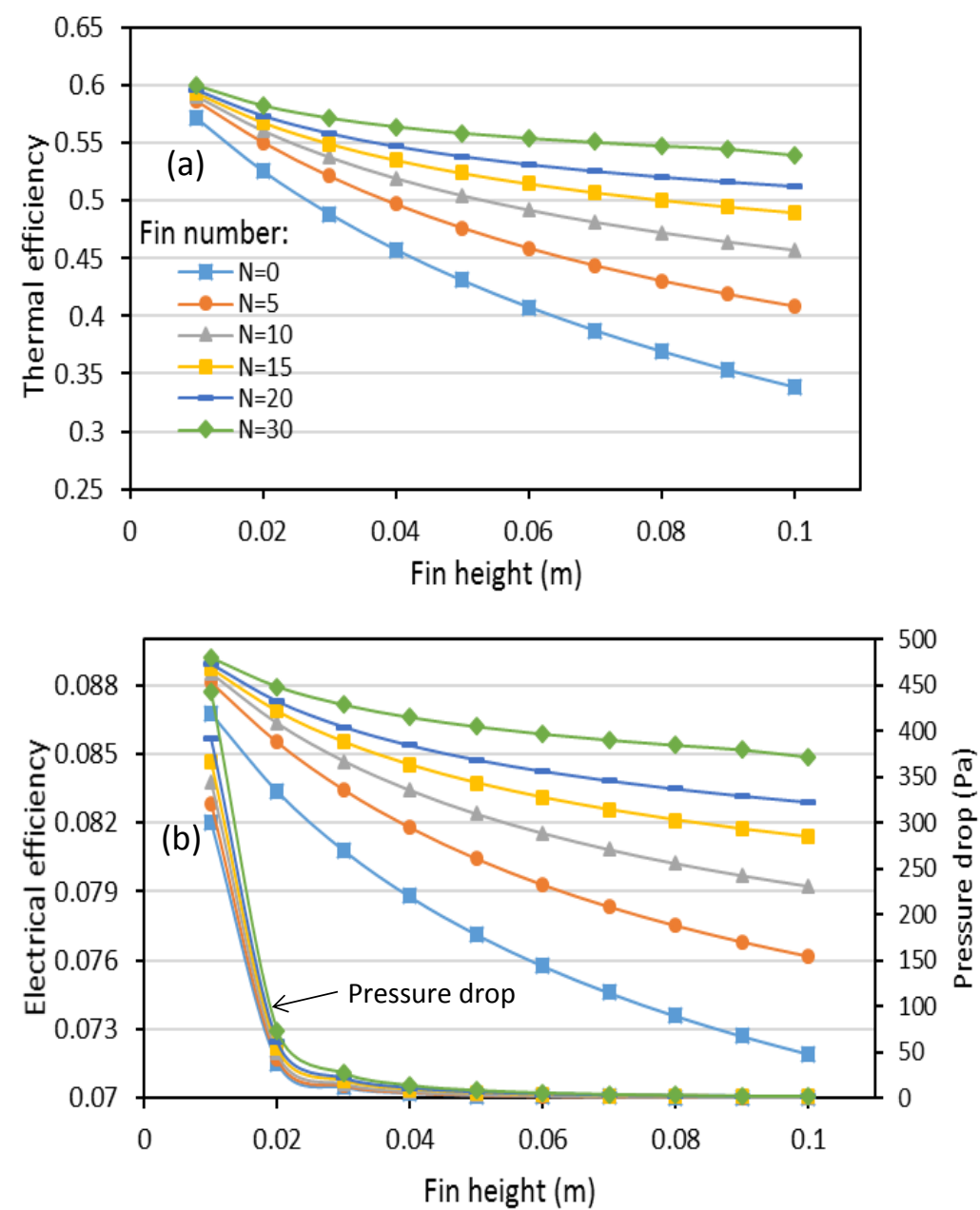

Figure 18. Thermal efficiency (a), electrical efficiency and pressure drop (b) of PVTSAH versus fin height and for different number of fins.

convective heat transfer in the air channel. The change of pressure drop is more sensitive to the height of fins than the number of fins. The results show that the 
pressure drop is significantly high when the fin height is less than $0.02 \mathrm{~m}$ (Figure 18b). For the specific case of this section, the optimum selection of fin height will be in the range of 0.02 to $0.04 \mathrm{~m}$, which corresponds to a small pressure drop and a comparatively high thermal and electrical efficiency. It can also be seen from Figure 18 that above a specific fin number, the efficiency improvement will be less significant, while the manufacturing and installation cost could in practice be higher. Therefore, the decision of the required fin number is an optimisation problem that should take both performance and local manufacturing cost into account.

\section{Effect of PV covering factor on the performance of the PVT-SAH system}

This section will demonstrate the application of the dynamic model of PVT-SAH to investigate the influence of the percentage areas of PVT on the thermal and electrical gains of the whole hybrid system. The term "PV covering factor $(\zeta)$ " is introduced in the present study to define the ratio of PVT area to the total PVT-SAH area. Five discrete values of the PV covering factor $\zeta$ of $0,0.25,0.5,0.75$ and 1.0 are chosen to conduct comparative performance simulations. Spectrally selective coating materials (emissivity $\varepsilon=0.05$ ) are applied on the absorber plate of SAH to reduce the longwave radiation heat loss. The combined thermal and electrical efficiency [57] is employed as an indicator to evaluate the performance of PVT-SAH system as shown below:

$\eta_{o}=\eta_{t h}+\zeta \eta_{e l e}$

The overall performance is also alternatively evaluated by the primary energy savings criterion [58] as shown below:

$E_{f}=\eta_{t h}+\zeta \eta_{\text {ele }} / \eta_{\text {power }}$

where $\eta_{\text {power }}$ is the average electric-power generation efficiency for a conventional power plant in Australia and 0.35 is used in this study [59]. 
The daily variation of four operation parameters: outlet air temperature; average PV plate temperature; instantaneous thermal energy gains and electrical efficiency with different PV covering factors are presented in Figures 19 and 20.

As expected, the outlet air temperature is decreased as the covering factor $\zeta$ increase (Figure 19 (a)) because the PVT is less efficient than the SAH when transferring heat to the flowing air. On the contrary, the average PV module temperature increased for higher PV cell covering factors (Figure 20 (a)).
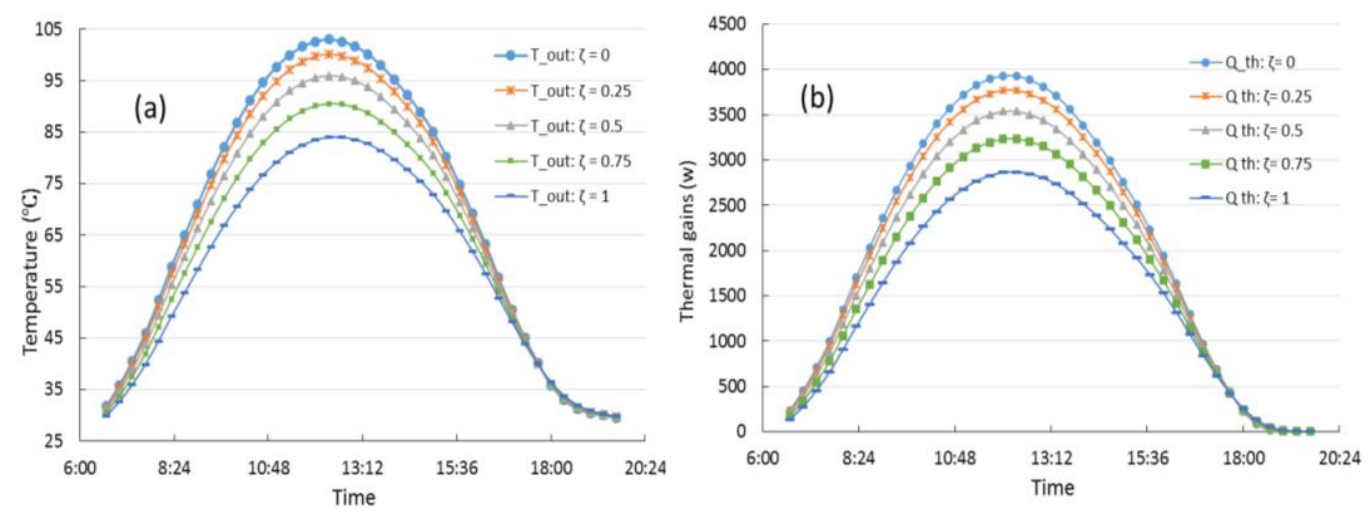

Figure 19. The instantaneous (a) outlet air temperature and (b) thermal gains with the variation of PV covering factor.
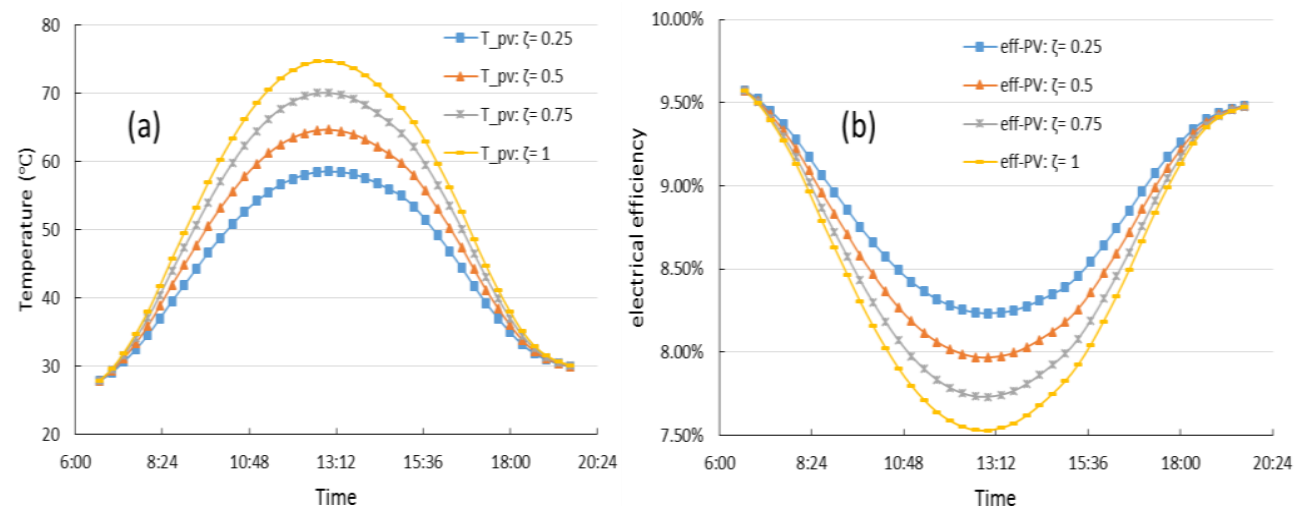

Figure 20. The instantaneous (a) mean PV temperature and (b) electrical efficiency with the variation of PV covering factor.

Table 6 summarises the useful thermal and electricity gains and the results for the two different performance $\operatorname{criteria}\left(\eta_{o}\right.$ and $\left.E_{f}\right)$. It is found that the electrical efficiency decreased with increasing covering factor, and this efficiency reduction reached up to $5.8 \%$ when the covering factor increased from 0.25 to 1 . When using the combined 
efficiency criterion $\left(\eta_{o}\right)$, the best performance was achieved by the hybrid PVT-SAH system with a PV covering factor of 0.25 which is followed by pure SAH. Considering the electricity is of higher grade, the analysis showed that the equal weighted PVT-SAH $(\zeta=0.5)$ probably the optimum design which performed the highest primary-energy saving efficiency $\left(E_{f}\right)$ of $70.6 \%$.

Table 6 Daily simulation results of thermal and electrical performance with different PV covering factors

\begin{tabular}{cccccccc}
\hline \multirow{2}{*}{$\begin{array}{l}\text { Covering } \\
\text { factor }\end{array}$} & \multirow{2}{*}{$\begin{array}{l}\text { Daily incident } \\
\text { solar radiation } \\
\text { (MJ/day) }\end{array}$} & \multirow{2}{*}{$\begin{array}{c}\text { Thermal } \\
\text { gains }\end{array}$} & \multirow{2}{*}{$\begin{array}{c}\text { Electricity } \\
\text { gains }\end{array}$} & \multicolumn{4}{c}{ Efficiency (\%) } \\
\cline { 6 - 8 } & (MJ/day) & $\eta_{\text {th }}$ & $\eta_{\text {ele }}$ & $\eta_{o}$ & $E_{f}$ \\
\hline$\zeta=0$ & 157 & 100.4 & 0 & 63.8 & 0 & 63.8 & 63.8 \\
$\zeta=0.25$ & 157 & 97.5 & 3.6 & 62.0 & 9.1 & 64.3 & 68.5 \\
$\zeta=0.5$ & 157 & 92.1 & 6.6 & 58.6 & 8.4 & 62.8 & 70.6 \\
$\zeta=0.75$ & 157 & 82.5 & 9.8 & 52.5 & 8.2 & 58.7 & 70.1 \\
$\zeta=1$ & 157 & 70.6 & 12.8 & 45.5 & 8.1 & 53.6 & 65.2 \\
\hline
\end{tabular}

\section{Conclusions}

A dynamic model for a hybrid PVT-SAH system that incorporates fins within the air channels was developed to enable system performance evaluations under real operational conditions. The finite volume technique was employed using the CrankNicolson scheme to develop the energy balance equations for all components and the air flowing through the channels of the PVT-SAH system. The dynamic model was validated by the experimental data tested under real operational conditions and by comparing with the reference data from the literature. Acceptable agreements between the modelling results and the measurements were observed with RMSD values varied from 0.3 to $1.3^{\circ} \mathrm{C}$. It was found that the use of a dynamic model could be important because the system could have significant Time Constants if the boundary conditions change in a dynamic manner. In addition, it was demonstrated that a steady state model could result in considerable prediction differences than those obtained from the dynamic model under dynamic working conditions. 
The dynamic model is not computationally demanding and could therefore be applicable for fast online applications. In addition, the present model allows for flexible inputs of design parameters and operational conditions, so that the performance of PVT-SAH with a variety of design scenarios can be evaluated and compared for optimum design. The case study in section 7 demonstrated how the present dynamic model could be applied to determine the design parameters of PVTSAH systems.

\section{Acknowledgements}

The authors would like to thank China Scholarship Council for supporting this study. 


\section{Appendix A}

Table 7 (a). Heat transfer coefficients used in the model

Overall heat loss coefficients from the top

$$
U_{t, p v}=\left(\frac{1}{h_{n c}+h_{r, p v-g}}+\frac{1}{h_{w}+h^{\prime} r, g-s k y}\right)^{-1}
$$

Overall heat loss coefficient from PV plate to ambient

In which $h_{r, g-s k y}^{\prime}$ refers to ambient temperature and is modified from $h_{r, g-s k y}$ (Eq. (21) which refer to sky temperature) by

multiplying Eq. (21) with $\frac{T_{g}-T_{s k y}}{T_{g}-T_{a m b}}$

Overall heat loss coefficient from absorber plate to ambient

$$
U_{t, p}=\left(\frac{1}{h_{n c}+h_{r, p-g}}+\frac{1}{h_{w}+h_{r, g-s k y}}\right)^{-1}
$$

Radiation heat transfer coefficients

Radiation coefficient from glass to sky[60]

Radiation coefficient from absorber plate to glass

Radiation coefficient from PV plate to glass

Radiation coefficient from absorber to bottom plate

$$
\begin{aligned}
& h_{r, g-s k y}=\varepsilon_{g} \sigma\left(T_{g}+T_{s k y}\right)\left(T_{g}^{2}+T_{s k y}^{2}\right) \\
& h_{r, p-g}=\frac{\sigma\left(T_{p}+T_{g}\right)\left(T_{p}^{2}+T_{g}^{2}\right)}{\frac{1}{\varepsilon_{p}}+\frac{1}{\varepsilon_{g}}-1} \\
& h_{r, p v-g}=\frac{\sigma\left(T_{p v}+T_{g}\right)\left(T_{p v}^{2}+T_{g}^{2}\right)}{\frac{1}{\varepsilon_{p v}}+\frac{1}{\varepsilon_{g}}-1} \\
& h_{r, p-b}=\frac{\sigma\left(T_{p}+T_{b}\right)\left(T_{p}^{2}+T_{b}^{2}\right)}{\frac{1}{\varepsilon_{p}}+\frac{1}{\varepsilon_{b}}-1}
\end{aligned}
$$

Convection heat transfer coefficients

Wind convection coefficient on glass cover[61]

$h_{w}=2.8+3.3 V_{w}$

Convection heat transfer coefficient in air channel [60]

$N u=N u_{\infty}+\frac{a\left(\frac{R e \operatorname{Pr} D_{h}}{L}\right)^{m}}{1+b\left(\frac{\operatorname{RePr} D_{h}}{L}\right)^{n} \operatorname{Pr} 0.17} \quad$ when $R e \leq 2300$

Where $N u_{\infty}=4.9 ; \mathrm{a}=0.0606, \mathrm{~b}=0.0909, \mathrm{~m}=1.2, \mathrm{n}=0.7$

$\mathrm{Nu}=0.0158 R e^{0.8}$

when $R e>2300$ 


$$
\begin{gathered}
h_{n c}=\frac{N u K_{f}}{d} \\
\mathrm{Nu}=1+1.44\left[1-\frac{1708(\sin 1.8 \varnothing)^{1.6}}{R a \cos \emptyset}\right]\left[1-\frac{1708}{R a \cos \emptyset}\right]^{+}+\left[\left(\frac{R a \cos \emptyset}{5380}\right)^{\frac{1}{3}}-1\right]^{+}
\end{gathered}
$$

Where $0 \leq \emptyset \leq 60^{\circ}$ and $0 \leq \mathrm{Ra} \leq 10^{5}$ and notation [ $]^{+}$means the value of the term in the bracket is set to zero if the lculated value is negative

Conduction heat transfer coefficients

Conduction heat transfer coefficient between PV plate to absorber plate

Conduction heat loss coefficient through bottom plate

$$
\begin{aligned}
& h_{p v-p}=\frac{1}{R_{a d}+R_{p}} \\
& \text { Where } R_{a d}=\frac{\Delta y_{a d}}{K_{a d}} \text { and } R_{p}=\frac{\Delta y_{p}}{K_{p}} \\
& U_{b}=\frac{1}{R_{i n s u}+R_{w}}
\end{aligned}
$$

\begin{tabular}{|c|c|c|}
\hline net absorbed radiation for $\mathrm{SAH}[60]$ & $\mathrm{S}=\operatorname{IAM}(\tau \alpha)_{n} I_{t}$ & $(30)$ \\
\hline PV efficiency[63] & $\eta_{p v}=\eta_{\circ}\left(1-0.0045\left[T_{p v}-25^{\circ} \mathrm{C}\right]\right)$ & $(31)$ \\
\hline Available radiation for PVT & $\mathrm{S}=\operatorname{IAM}(\tau \alpha)_{n} I_{t}\left(1-\eta_{p v}\right)$ & $(32)$ \\
\hline Incidence Angle modifier (IAM) [60] & $I A M=\frac{(\tau \alpha)_{\theta}}{(\tau \alpha)_{n}}=\frac{I_{b} \frac{(\tau \alpha)_{b}}{(\tau \alpha)_{n}}}{I_{t}}+\frac{I_{d} \frac{(1+\cos \emptyset)}{2} \frac{(\tau \alpha)_{d}}{(\tau \alpha)_{n}}}{I_{t}}+\frac{I_{h} \rho \frac{(1+\cos \emptyset)}{2} \frac{(\tau \alpha)_{h}}{(\tau \alpha)_{n}}}{I_{t}}$ & (33) \\
\hline
\end{tabular}

Table 7(b). The net absorbed solar radiation for heat transfer

\section{Net absorbed radiation}




\section{Appendix B}

Table 8. Matrix coefficients in Eq. (14) and Eq. (15)

\begin{tabular}{|c|c|c|}
\hline $\begin{array}{l}\text { PVT } \\
\end{array}$ & SAH & Coefficient expressions \\
\hline$E_{1,1}$ & $E_{1,1}^{\prime}$ & $E_{1,1}: C_{g} M_{g}+(1-\gamma) \Delta t\left(h_{n c}^{t+\Delta t}+h_{r, p v-g}^{t+\Delta t}+h_{w}^{t+\Delta t}+h_{r, g-a}^{t+\Delta t}\right) ; \quad E_{1,1}^{\prime}$ : replace the subscript 'pv' in $E_{1,1}$ with 'p'. \\
\hline$E_{1,2}$ & $E_{1,2}^{\prime}$ & $E_{1,2}:\left[(\gamma-1) \Delta t\left(h_{n c}^{t+\Delta t}+h_{r, p v-g}^{t+\Delta t}\right)\right] ; E_{1,2}^{\prime}$ : replace the subscript 'pv' in $E_{1,1}$ with 'p'. \\
\hline$E_{2,2}$ & & {$\left[C_{p v} M_{p v}+(1-\gamma) \Delta t\left(U_{t}^{t+\Delta t}+h_{p v-p}^{t+\Delta t}\right)\right]$} \\
\hline$E_{2,3}$ & & $(\gamma-1) \Delta t h_{p v-p}^{t+\Delta t}$ \\
\hline$E_{3,2}$ & & $(\gamma-1) \Delta t h_{p v-p}^{t+\Delta t}$ \\
\hline$E_{3,3}$ & $E_{2,2}^{\prime}$ & $E_{3,3}:\left[C_{p} M_{p}+(1-\gamma) \Delta t\left(h_{p v-p}^{t+\Delta t}+h_{c, p-f}^{t+\Delta t}+h_{r, p-b}^{t+\Delta t}+\frac{2 C K_{f i n}}{H_{f i n}}\right)\right] ; E_{2,2}^{\prime}:$ Replace $h_{p v-p}^{t+\Delta t}$ in $E_{3,3}$ with $U_{t}^{t+\Delta t}$ \\
\hline$E_{3,4}$ & $E_{2,3}^{\prime}$ & $(\gamma-1) \Delta t\left(\frac{2 C K_{\text {fin }}}{H_{\text {fin }}}\right)$ \\
\hline$E_{3,5}$ & $E_{2,4}^{\prime}$ & $E_{3,5}:(\gamma-1) \Delta t h_{c, p-f}^{t+\Delta t}$ \\
\hline$E_{3,6}$ & $E_{2,5}^{\prime}$ & $E_{3,6}:(\gamma-1) \Delta t h_{r, p-b}^{t+\Delta t}$ \\
\hline$E_{4,3}$ & $E_{3,2}^{\prime}$ & $(\gamma-1) \Delta \mathrm{t}\left(\frac{2 e K_{\text {fin }}}{H_{\text {fin }}}\right)$ \\
\hline$E_{4,4}$ & $E_{3,3}^{\prime}$ & $C_{f i n} M_{f i n}+(1-\gamma) \Delta \mathrm{t}\left(\frac{4 e K_{f i n}}{H_{f i n}}+2 h_{c, f i n-f}^{t+\Delta t}\right)$ \\
\hline$E_{4,5}$ & $E_{3,4}^{\prime}$ & $-2(1-\gamma) \Delta \mathrm{t} h_{c, f i n-f}^{t+\Delta t}$ \\
\hline$E_{4,6}$ & $E_{3,5}^{\prime}$ & $-(1-\gamma) \Delta \mathrm{t}\left(\frac{2 e K_{f i n}}{H}\right)$ \\
\hline$E_{5,3}$ & $E_{4,2}^{\prime}$ & $(\gamma-1) \Delta t A h_{c, p-f}^{t+\Delta t}$ \\
\hline$E_{5,4}$ & $E_{4,3}^{\prime}$ & $(\gamma-1) \Delta t\left(2 A_{f i n}\right) h_{c, p-f}^{t+\Delta t}$ \\
\hline$E_{5,5}$ & $E_{4,4}^{\prime}$ & $C_{f} \rho_{f}\left(W H_{c}\right) \Delta x+(1-\gamma)\left(2 \Delta t A h_{c, p-f}^{t+\Delta t}+2 A_{f i n} \Delta t h_{c, f i n-f}^{t+\Delta t}+2 C_{f} M_{f} \dot{\Delta} t\right)$ \\
\hline$E_{5,6}$ & $E_{4,5}^{\prime}$ & $(\gamma-1) \Delta t A h_{c, b-f}^{t+\Delta t}$ \\
\hline$E_{6,3}$ & $E_{5,2}^{\prime}$ & $(\gamma-1) \Delta t h_{r, p-b}^{t+\Delta t}$ \\
\hline$E_{6,4}$ & $E_{5,3}^{\prime}$ & $(\gamma-1) \Delta t\left(\frac{2 C K_{f i n}}{H_{f i n}}\right)$ \\
\hline$E_{6,5}$ & $E_{5,4}^{\prime}$ & $(\gamma-1) \Delta t h_{c, b-f}^{t+\Delta t}$ \\
\hline$E_{6,6}$ & $E_{5,5}^{\prime}$ & $C_{b} M_{b}+(1-\gamma) \Delta t\left(\frac{2 C K_{f i n}}{H_{f i n}}+h_{r, p-b}^{t+\Delta t}+h_{c, b-f}^{t+\Delta t}+U_{b}\right)$ \\
\hline
\end{tabular}




\begin{tabular}{|c|c|c|}
\hline PVT & SAH & Coefficient expressions \\
\hline$Q_{1}$ & $Q_{1}^{\prime}$ & $\begin{array}{l}Q_{1}:\left[C_{g} M_{g}-\gamma \Delta t\left(h_{n c}^{t}+h_{r, p v-g}^{t}+h_{w}^{t}+h_{r, g-a}^{t}\right)\right] T_{g, i}^{t}+\left[\gamma \Delta t\left(h_{n c}^{t}+h_{r, p v-g}^{t}\right)\right] T_{p v, i}^{t}+\gamma \Delta t\left[\alpha_{g} I_{t}^{t}+h_{w}^{t} T_{a m b}^{t}+h_{r, g-a}^{t} T_{s k y}^{t}\right]+(1-\gamma) \Delta t\left[\alpha_{g} I_{t}^{t+\Delta t}+h_{w}^{t+\Delta t} T_{a m b}^{t+\Delta t}+\right. \\
\left.h_{r, g-a}^{t+\Delta t} T_{s k y}^{t+\Delta t}\right] ; \quad Q_{1}^{\prime}: \text { replace the subscript 'pv' in } Q_{1} \text { with 'p'. }\end{array}$ \\
\hline$Q_{2}$ & & $\begin{array}{l}{\left[C_{p v} M_{p v}-\gamma \Delta t\left(U_{t}^{t}+h_{p v-p}^{t}\right)\right] T_{p v, i}^{t}+\gamma \Delta t h_{p v-p}^{t} T_{p, i}^{t}+\gamma \Delta t U_{t}^{t} T_{a m b}^{t}+(1-\gamma) \Delta t U_{t}^{t+\Delta t} T_{a m b}^{t+\Delta t}+\gamma \Delta t\left(\tau_{g} \alpha_{p v}\right) I_{t}^{t}\left(1-\eta_{p v}^{t}\right)+(1} \\
-\gamma) \Delta t\left(\tau_{g} \alpha_{p v}\right) I_{t}^{t+\Delta t}\left(1-\eta_{p v}^{t+\Delta t}\right)\end{array}$ \\
\hline$Q_{3}$ & $Q_{2}^{\prime}$ & $\begin{array}{l}Q_{3}: \gamma \Delta t h_{p v-p}^{t} T_{p v, i}^{t}+\left[C_{p} M_{p}-\gamma \Delta t\left(h_{p v-p}^{t}+h_{c, p-f}^{t}+h_{r, p-b}^{t}+\frac{2 C K_{f i n}}{H_{f i n}}\right] T_{p, i}^{t}+\gamma \Delta t\left(\frac{2 C K_{f i n}}{H_{f i n}}\right) T_{f i n, i}^{t}+\gamma \Delta t h_{c, p-f}^{t} T_{f . i}^{t}+\gamma \Delta t h_{r, p-b}^{t} T_{b . i}^{t+\Delta t}\right. \\
Q_{2}^{\prime}:\left[C_{p} M_{p}-\gamma \Delta t\left(U_{t}^{t}+h_{c, p-f}^{t}+h_{r, p-b}^{t}+\frac{2 C K_{f i n}}{H_{f i n}}\right)\right] T_{p, i}^{t}+\gamma \Delta t\left(\frac{2 C K_{f i n}}{H_{f i n}}\right) T_{f i n, i}^{t}+\gamma \Delta t h_{c, p-f}^{t} T_{f, i}^{t}+\gamma \Delta t h_{r, p-b}^{t} T_{b, i}^{t}+\gamma \Delta t\left(\tau_{g} \sigma_{p}\right) I_{t}^{t}+(1-\gamma) \Delta t\left(\tau_{g} \sigma_{p}\right) I_{t}^{t+\Delta t}+ \\
\gamma \Delta t U_{t}^{t} T_{a m b}^{t}+(1-\gamma) \Delta t U_{t}^{t+\Delta t} T_{a m b}^{t+\Delta t}\end{array}$ \\
\hline$Q_{4}$ & $Q_{3}^{\prime}$ & $\gamma \Delta \mathrm{t}\left(\frac{2 e K_{f i n}}{H_{f i n}}\right) T_{p, i}^{t}+\left[C_{f i n} M_{f i n}-\gamma \Delta \mathrm{t}\left(\frac{4 e K_{f i n}}{H_{f i n}}+2 h_{c, f i n-f}^{t}\right)\right] T_{f i n, i}^{t}+2 \gamma \Delta \mathrm{t} h_{c, f i n-f}^{t} T_{f, i}^{t}+\gamma \Delta \mathrm{t}\left(\frac{2 e K_{f i n}}{H_{f i n}}\right) T_{b, i}^{t}$ \\
\hline$Q_{5}$ & $Q_{4}^{\prime}$ & $\begin{aligned} \gamma \Delta t A h_{c, p-f}^{t} T_{p, i}^{t} & +\gamma \Delta t\left(2 A_{f i n}\right) h_{c, f i n-f}^{t} T_{f i n, i}^{t}+\left[C_{f} \rho_{f}\left(W H_{c}\right) \Delta x+\gamma\left(2 \Delta t A h_{c, p-f}^{t}+2 A_{f i n} \Delta t h_{c, f i n-f}^{t}+2 C_{f} M_{f} \dot{\Delta} t\right)\right] T_{f, i}^{t}+\gamma \Delta t A h_{c, b-f}^{t} T_{b, i}^{t}+2 \gamma \Delta t C_{f} \dot{M}_{f} T_{i n, i}^{t} \\
& +2(1-\gamma) \Delta t C_{f} \dot{M}_{f} T_{i n, i}^{t+\Delta t}\end{aligned}$ \\
\hline$Q_{6}$ & $Q^{\prime}{ }_{5}$ & $\gamma \Delta t h_{r, p-b}^{t} T_{p, i}^{t}+\gamma \Delta t\left(\frac{2 C K_{f i n}}{H_{f i n}}\right) T_{f i n, i}^{t}+\gamma \Delta t h_{c, b-f}^{t} T_{f, i}^{t}+\left[C_{b} M_{b}-\gamma \Delta t\left(\frac{2 C K_{f i n}}{H_{f i n}}+h_{r, p-b}^{t}+h_{c, b-f}^{t}+U_{b}\right)\right] T_{b, i}^{t}+\gamma \Delta t U_{b} T_{a m b}^{t}+(1-\gamma) \Delta t U_{b} T_{a m b}^{t+\Delta t}$ \\
\hline
\end{tabular}




\section{References}

[1] Nia FE, Van Paassen D, Saidi MH. Modeling and simulation of desiccant wheel for air conditioning. Energy and Buildings. 2006;38:1230-9.

[2] Yeh H-M, Ho C-D, Hou J-Z. Collector efficiency of double-flow solar air heaters with fins attached. Energy. 2002;27:715-27.

[3] Matrawy K. Theoretical analysis for an air heater with a box-type absorber. Solar energy. 1998;63:191-8.

[4] Kabeel A, Mečárik K. Shape optimization for absorber plates of solar air collectors. Renewable Energy. 1998;13:121-31.

[5] Alfegi EMA, Sopian K, Othman MYH, Yatim BB. The effect of flow rates on the performance of finned single pass, double duct photovoltaic thermal solar air heaters. European Journal of Scientific Research. 2009;25:339-44.

[6] Alfegi MEA, Sopian K, Othman MYH, Yatim BB. Experimental investigation of single pass, double duct photovoltaic thermal (PV/T) air collector with CPC and fins. American Journal of applied sciences. 2008;5:866-71.

[7] Othman MYH, Yatim B, Sopian K, Bakar MNA. Performance analysis of a double-pass photovoltaic/thermal (PV/T) solar collector with CPC and fins. Renewable energy. 2005;30.

[8] Othman MY, Yatim B, Sopian K, Bakar MNA. Performance studies on a finned double-pass photovoltaic-thermal (PV/T) solar collector. Desalination. 2007;209:43-9.

[9] Othman M, Yatim B, Sopian K, Bakar M. Double-pass photovoltaic-thermal solar air collector with compound parabolic concentrator and fins. Journal of energy engineering. 2006;132:116-20.

[10] Tchinda R. A review of the mathematical models for predicting solar air heaters systems. Renewable and sustainable energy reviews. 2009;13:1734-59.

[11] Tonui J, Tripanagnostopoulos Y. Air-cooled PV/T solar collectors with low cost performance improvements. Solar energy. 2007;81:498-511.

[12] Garg H, Agarwal R. Some aspects of a PV/T collector/forced circulation flat plate solar water heater with solar cells. Energy Conversion and Management. 1995;36:87-99.

[13] Shahsavar A, Ameri M. Experimental investigation and modeling of a direct-coupled PV/T air collector. Solar Energy. 2010;84:1938-58.

[14] Garg H, Adhikai R. Conventional hybrid photovoltaic/thermal air heating collectors \| . Renewable energy. 1997;8:363-85.

[15] Cox C, Raghuraman P. Design considerations for flat-plate-photovoltaic/thermal collectors. Solar energy. 1985;35:227-41.

[16] Sopian K, Liu H, Kakac S, Veziroglu T. Performance of a double pass photovoltaic thermal solar collector suitable for solar drying systems. Energy Conversion and Management. 2000;41:353-65.

[17] Morita Y, Fujisawa T, Tani T. Moment performance of photovoltaic/thermal hybrid panel (numerical analysis and exergetic evaluation). Electrical Engineering in Japan. 2000;133:43-51.

[18] Bambrook S, Sproul A. Maximising the energy output of a PVT air system. Solar Energy. 2012;86:1857-71.

[19] Schnieders J. Comparison of the energy yield predictions of stationary and dynamic solar collector models and the models' accuracy in the description of a vacuum tube collector. Solar Energy. 1997;61:179-90.

[20] Hottel H, Whillier A. Evaluation of flat-plate solar collector performance. Trans Conf Use of Solar Energy;()1955.

[21] Florschuetz L. Extension of the Hottel-Whillier model to the analysis of combined photovoltaic/thermal flat plate collectors. Solar energy. 1979;22:361-6. 
[22] Standard A. Standard 93-2003 "Methods of testing to determine the performance of solar collectors", ASHRAE. Atlanta. 2003.

[23] Standard B, EN B. EN 12975-2: 2006, Thermal solar systems and components. Solar collectors. Test methods. 2006.

[24] Klein S, Beckman W, Mitchell J, Duffie J, Duffie N, Freeman T, et al. TRNSYS 16-A TRaNsient system simulation program, user manual. Solar Energy Laboratory Madison: University of Wisconsin-Madison. 2004.

[25] Choudhury C, Chauhan P, Garg H. Design curves for conventional solar air heaters. Renewable energy. 1995;6:739-49.

[26] Njomo D. Unglazed selective absorber solar air collector: heat exchange analysis. Heat and mass transfer. 2000;36:313-7.

[27] Naphon P, Kongtragool B. Theoretical study on heat transfer characteristics and performance of the flat-plate solar air heaters. International communications in heat and mass transfer. 2003;30:1125-36.

[28] Zhai X, Dai Y, Wang R. Comparison of heating and natural ventilation in a solar house induced by two roof solar collectors. Applied Thermal Engineering. 2005;25:741-57.

[29] Yeh H-M, Ho C-D, Hou J-Z. The improvement of collector efficiency in solar air heaters by simultaneously air flow over and under the absorbing plate. Energy. 1999;24:857-71.

[30] Naphon P. On the performance and entropy generation of the double-pass solar air heater with longitudinal fins. Renewable Energy. 2005;30:1345-57.

[31] Hegazy AA. Performance of flat plate solar air heaters with optimum channel geometry for constant/variable flow operation. Energy Conversion and Management. 2000;41:401-17.

[32] Hegazy AA. Thermohydraulic performance of air heating solar collectors with variable width, flat absorber plates. Energy conversion and management. 2000;41:1361-78.

[33] Jha R, Choudhury C, Garg H, Zaidi ZH. Performance prediction of a solar heated house. 1992.

[34] Ucar A, Inallı M. Thermal and exergy analysis of solar air collectors with passive augmentation techniques. International communications in heat and mass transfer. 2006;33:1281-90.

[35] Jain D, Jain RK. Performance evaluation of an inclined multi-pass solar air heater with inbuilt thermal storage on deep-bed drying application. Journal of Food Engineering. 2004;65:497-509.

[36] Jain D. Modeling the system performance of multi-tray crop drying using an inclined multi-pass solar air heater with in-built thermal storage. Journal of food engineering. 2005;71:44-54.

[37] Ramadan M, El-Sebaii A, Aboul-Enein S, El-Bialy E. Thermal performance of a packed bed double-pass solar air heater. Energy. 2007;32:1524-35.

[38] El-Sebaii A, Aboul-Enein S, Ramadan M, El-Bialy E. Year round performance of double pass solar air heater with packed bed. Energy Conversion and management. 2007;48:9901003.

[39] Wijeysundera N. Response time of solar collectors. Solar Energy. 1976;18:65-8.

[40] Arinze E, Schoenau G, Sokhansanj S, Adefila S, Mumah S. A dynamic performance simulation model of flat-plate solar collectors for a heat pump system. Energy conversion and management. 1993;34:33-49.

[41] Bosanac M, Brunotte A, Spirkl W, Sizmann R. The use of parameter identification for flat-plate collector testing under non-stationary conditions. Renewable energy. 1994;4:21722.

[42] Chow T. Performance analysis of photovoltaic-thermal collector by explicit dynamic model. Solar Energy. 2003;75:143-52.

[43] Sohel MI, Ma Z, Cooper P, Adams J, Scott R. A dynamic model for air-based photovoltaic thermal systems working under real operating conditions. Applied Energy. 2014;132:216-25. 
[44] Garg H, Chandra R, Rani U. Transient analysis of solar air heaters using a finite difference technique. International Journal of Energy Research. 1981;5:243-52.

[45] Varol Y, Oztop HF. A comparative numerical study on natural convection in inclined wavy and flat-plate solar collectors. Building and environment. 2008;43:1535-44.

[46] Kumar S, Saini R. CFD based performance analysis of a solar air heater duct provided with artificial roughness. Renewable Energy. 2009;34:1285-91.

[47] Karmare S, Tikekar A. Analysis of fluid flow and heat transfer in a rib grit roughened surface solar air heater using CFD. Solar Energy. 2010;84:409-17.

[48] Soi A, Singh R, Bhushan B. Effect of roughness element pitch on heat transfer and friction characteristics of artificially roughened solar air heater duct. International Journal of Advanced Engineering Technology. 2010;1:339-46.

[49] Sharma S, Singh R, Bhushan B. CFD based investigation on effect of roughness element pitch on performance of artificially roughened duct used in solar air heaters. International Journal of Advanced Engineering Technology. 2011;2:234-41.

[50] Corbin CD, Zhai ZJ. Experimental and numerical investigation on thermal and electrical performance of a building integrated photovoltaic-thermal collector system. Energy and Buildings. 2010;42:76-82.

[51] Li S, Karava P, Currie S, Lin WE, Savory E. Energy modeling of photovoltaic thermal systems with corrugated unglazed transpired solar collectors-Part 1: Model development and validation. Solar Energy. 2014;102:282-96.

[52] Naewngerndee R, Hattha E, Chumpolrat K, Sangkapes T, Phongsitong J, Jaikla S. Finite element method for computational fluid dynamics to design photovoltaic thermal (PV/T) system configuration. Solar Energy Materials and Solar Cells. 2011;95:390-3.

[53] Eymard R, Gallouët T, Herbin R. Finite volume methods. Handbook of numerical analysis. 2000;7:713-1018.

[54] Wang ZJ. Spectral (finite) volume method for conservation laws on unstructured grids. basic formulation: Basic formulation. Journal of Computational Physics. 2002;178:210-51.

[55] CIBSE GA. Environmental design. Chartered Institution of Building Services Engineers, London. 2006.

[56] Strachan P, Svehla K, Heusler I, Kersken M. Whole model empirical validation on a fullscale building. Journal of Building Performance Simulation. 2015:1-20.

[57] Garg H, Bharagaba A, Agarwal R. Experimental and theoretical studies on a photovoltaic/thermal hybrid solar collector water heater. Proceedings of ISES Solar World Congress1990. p. 701-5.

[58] Huang B, Lin T, Hung W, Sun F. Performance evaluation of solar photovoltaic/thermal systems. Solar energy. 2001;70:443-8.

[59] Graus W, Worrell E. Comparison of efficiency fossil power generation. Ecofys Utrecht, The Netherlands. 2006.

[60] Duffie JA, Beckman WA. Solar engineering of thermal processes: Wiley New York etc.; 1980.

[61] Watmuff J, Charters W, Proctor D. Solar and wind induced external coefficients for solar collectors. Comples, 2. Rev Inter Heliotech, Marseille. 1977.

[62] Hollands K, Unny T, Raithby G, Konicek L. Free convective heat transfer across inclined air layers. Journal of Heat Transfer. 1976;98:189-93.

[63] Zondag H, De Vries D, Van Helden W, Van Zolingen R, Van Steenhoven A. The yield of different combined PV-thermal collector designs. Solar energy. 2003;74:253-69. 